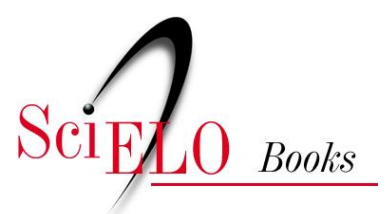

\title{
Ordem Aulopiformes
}

\author{
Ana Cristina Teixeira Bonecker \\ Claudia Akemi Pereira Namiki \\ Márcia Salustiano de Castro \\ Paula Nepomuceno Campos
}

\section{SciELO Books / SciELO Livros / SciELO Libros}

BONECKER, ACT., et al. Ordem Aulopiformes. In Catalogo dos estágios iniciais de

desenvolvimento dos peixes da bacia de Campos [online]. Curitiba: Sociedade Brasileira de Zoologia, 2014, pp. 70-97. Zoologia: guias e manuais de identificação series. ISBN 978-85-98203-10-2.

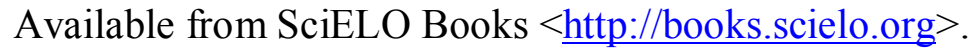

\section{(2)(1)(2)}

All the contents of this chapter, except where otherwise noted, is licensed under a Creative Commons Attribution-Non Commercial-ShareAlike 3.0 Unported.

Todo o conteúdo deste capítulo, exceto quando houver ressalva, é publicado sob a licença Creative Commons Atribuição Uso Não Comercial - Partilha nos Mesmos Termos 3.0 Não adaptada.

Todo el contenido de este capítulo, excepto donde se indique lo contrario, está bajo licencia de la licencia Creative Commons Reconocimento-NoComercial-CompartirIgual 3.0 Unported. 


\section{ORDEM AULOPIFORMES}

A ordem Aulopiformes é composta por 15 famílias e quatro subordens, com hábitos pelágicos, mesopelágicos, batipelágicos e bentônicos. A principal característica que é comum a todas as famílias dessa ordem, com exceção da família Notosudidae, é a presença de pigmentos peritoneais.

Nesse estudo a ordem Aulopiformes é representada pelas famílias Scopelarchidae, Notosudidae, Synodontidae, Paralepididae e Evermannellidae. 


\section{Família Scopelarchidae}

A família Scopelarchidae ocorre em todos os oceanos com exceção do Ártico e do Mar Mediterrâneo. Compreende quatro gêneros com 17 espécies. As larvas de Scopelarchidae podem apresentar corpo fino e alongado ou alto e curto. Possuem de 0-3 seções peritoneais, dependendo da espécie. Os olhos são elípticos e tubulares, normalmente voltados para cima. A posição das nadadeiras pélvicas ajuda na separação dos gêneros e o padrão dos pigmentos acessórios é utilizado na identificação das espécies.

No Brasil já foram identificadas seis espécies nas fases de larva e adulto. Nesse estudo são contempladas as espécies Benthalbella infans e Scopelarchus sp. 


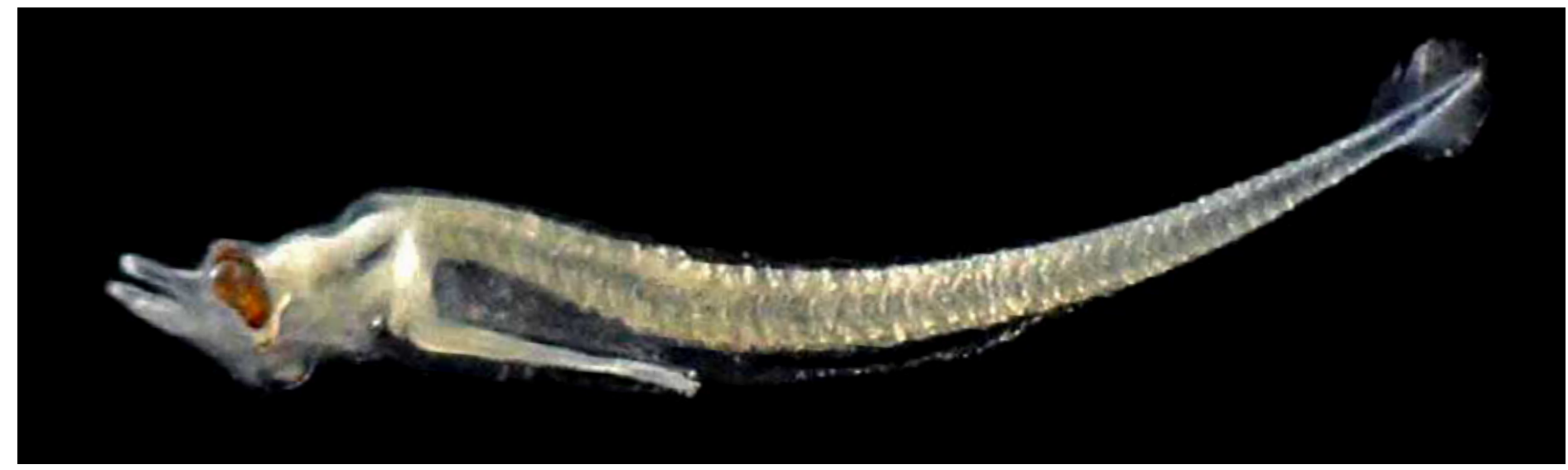

Figura 36 - A: Benthalbella infans. DZUFRJ 17630; Pré-flexão; CP 6,5 mm.

\section{Benthalbella infans Zugmayer, 1911}

As larvas do gênero Benthalbella não apresentam seção peritoneal e nenhum tipo de pigmentação no corpo. As nadadeiras pélvicas estão inseridas antes do início da nadadeira dorsal. O número de vértebras varia entre 54 e 65.

Tamanho: pré-flexão 6,5 mm; flexão 12,0-15,0 mm; pós-flexão $16,0 \mathrm{~mm}$.

Habitat: todas as espécies de Benthalbella encontradas na literatura são marinhas e batipelágicas, ocorrem até $3.400 \mathrm{~m}$ de profundidade.

\section{Georreferenciamento}

\begin{tabular}{|c|c|c|c|c|c|c|c|c|}
\hline DZUFRJ & Latitude (S) & Longitude (W) & Data & $\begin{array}{c}\text { Tipo de } \\
\text { arrasto }\end{array}$ & $\begin{array}{c}\text { Profundidade } \\
\text { de coleta }\end{array}$ & Rede & $\begin{array}{c}\text { Malha } \\
(\boldsymbol{\mu m})\end{array}$ & $\begin{array}{c}\mathbf{N}^{\circ} \text {. de } \\
\text { inds. }\end{array}$ \\
\hline 1186 & $22^{\circ} 07^{\prime} 29,0^{\prime \prime}$ & $039^{\circ} 06^{\prime} 23,5^{\prime \prime}$ & $10 / 05 / 2002$ & oblíquo & $1.000 \mathrm{~m}$ & cilíndrico-cônica & 500 & 1 \\
\hline 1223 & $22^{\circ} 02^{\prime} 30,0^{\prime \prime}$ & $039^{\circ} 49^{\prime} 41,2^{\prime \prime}$ & $12 / 05 / 2002$ & oblíquo & $1.000 \mathrm{~m}$ & cilíndrico-cônica & 500 & 1 \\
\hline 5404 & $22^{\circ} 32^{\prime} 50,0^{\prime \prime}$ & $040^{\circ} 04^{\prime} 09,9^{\prime \prime}$ & $06 / 11 / 2001$ & oblíquo & $1.000 \mathrm{~m}$ & cilíndrico-cônica & 500 & 1 \\
\hline 7497 & $21^{\circ} 58^{\prime} 31,0^{\prime \prime}$ & $039^{\circ} 50^{\prime} 29,7^{\prime \prime}$ & $11 / 10 / 2001$ & oblíquo & $1.000 \mathrm{~m}$ & cilíndrico-cônica & 500 & 1 \\
\hline 7498 & $21^{\circ} 58^{\prime} 31,0^{\prime \prime}$ & $039^{\circ} 50^{\prime} 29,7^{\prime \prime}$ & $10 / 10 / 2001$ & oblíquo & $1.000 \mathrm{~m}$ & cilíndrico-cônica & 500 & 1 \\
\hline 17624 & $22^{\circ} 31^{\prime} 40,9^{\prime \prime}$ & $040^{\circ} 02^{\prime} 39,6^{\prime \prime}$ & $07 / 11 / 2001$ & oblíquo & $1.000 \mathrm{~m}$ & cilíndrico-cônica & 500 & 1 \\
\hline 17627 & $22^{\circ} 32^{\prime} 49,0^{\prime \prime}$ & $040^{\circ} 04^{\prime} 20,9^{\prime \prime}$ & $07 / 11 / 2001$ & oblíquo & $1.000 \mathrm{~m}$ & cilíndrico-cônica & 500 & 1 \\
\hline 17629 & $22^{\circ} 08,03^{\prime}$ & $039^{\circ} 50,1^{\prime}$ & $16 / 06 / 2003$ & vertical & $500 \mathrm{~m}$ & cilíndrico-cônica & 500 & 1 \\
\hline 17630 & $22^{\circ} 02,27^{\prime}$ & $039^{\circ} 43,49^{\prime}$ & $18 / 06 / 2003$ & vertical & $100-480 \mathrm{~m}$ & cilíndrico-cônica & 500 & 1 \\
\hline 17631 & $21^{\circ} 58^{\prime} 31,0^{\prime \prime}$ & $039^{\circ} 50^{\prime} 29,7^{\prime \prime}$ & $10 / 10 / 2001$ & oblíquo & $1.000 \mathrm{~m}$ & cilíndrico-cônica & 500 & 1 \\
\hline
\end{tabular}

Referências: Johnson, 1974; Bonecker et al., 2006b; Ditty, 2006a; Fahay, 2007. 


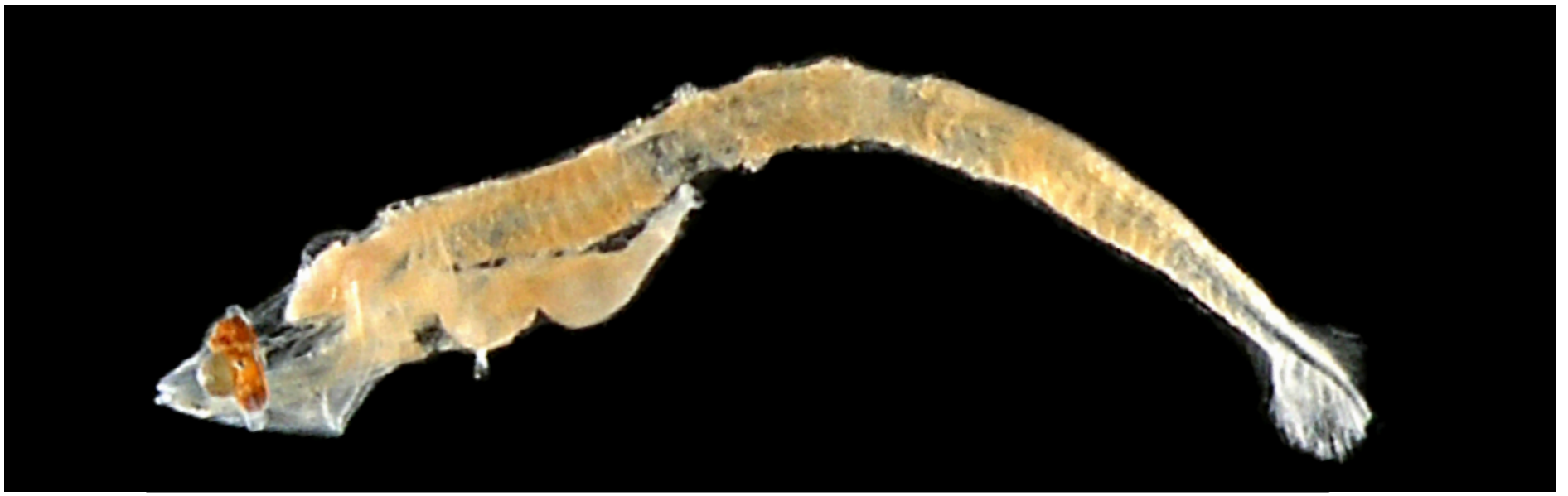

Figura 37 - A: Scopelarchus sp. DZUFRJ 5547; Pré-flexão; CP 5,3 mm.

\section{Scopelarchus sp.}

As larvas de Scopelarchus com mais de $15 \mathrm{~mm}$ de CP possuem pigmentos peritoneais. Pigmentos acessórios ausentes nas larvas menores que 10,0 mm CP. A origem das nadadeiras pélvicas é ventro-lateral, abaixo ou ao nível do intestino, localizada bem atrás da base da nadadeira dorsal. O número de vértebras varia entre 40 e 51 . No Brasil já foram coletadas as espécies Scopelarchus analis (Brauer, 1902), Scopelarchus guentheri Alcock, 1896 e Scopelarchus michaelsarsi Koefoed, 1955.

Tamanho: pré-flexão 4,0-5,3 mm; flexão 6,0-9,5 mm; pós-flexão 18,5 mm.

Habitat: todas as espécies de Scopelarchus registradas na literatura são marinhas e batipelágicas, ocorrem

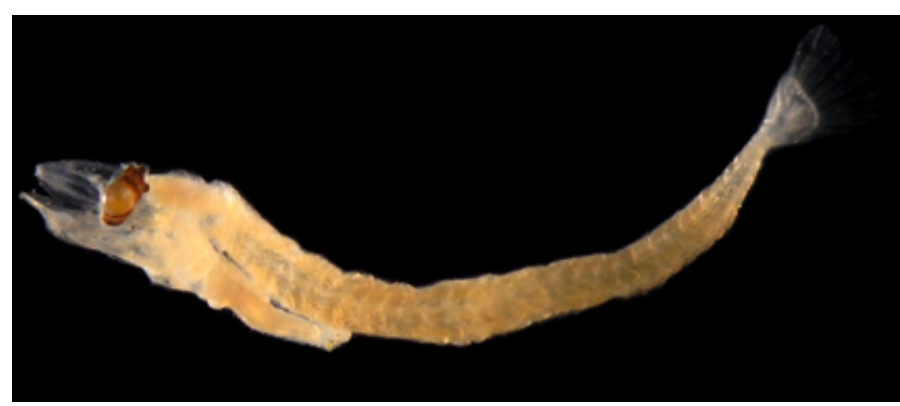

Figura 37 - B: DZUFRJ 17628; Flexão; CP 6,7 mm.

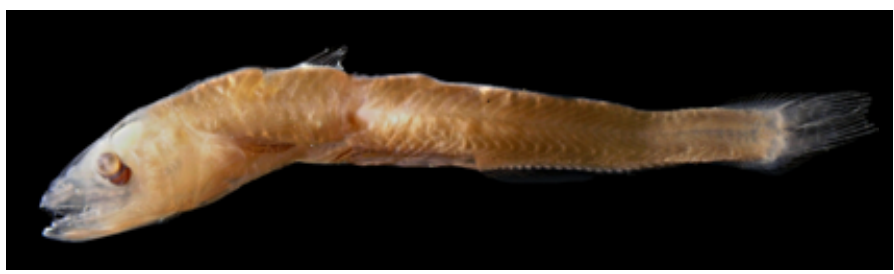

Figura 37 - C: DZUFRJ 7496; Pós-flexão; CP 18,5 mm. até $1.000 \mathrm{~m}$ de profundidade.

\section{Georreferenciamento}

\begin{tabular}{|c|c|c|c|c|c|c|c|c|}
\hline DZUFRJ & Latitude (S) & Longitude (W) & Data & $\begin{array}{l}\text { Tipo de } \\
\text { arrasto }\end{array}$ & $\begin{array}{c}\text { Profundidade } \\
\text { de coleta }\end{array}$ & Rede & $\begin{array}{c}\text { Malha } \\
(\mu \mathrm{m})\end{array}$ & $\begin{array}{l}N^{\circ} \text {. de } \\
\text { inds. }\end{array}$ \\
\hline 1212 & $22^{\circ} 02^{\prime} 30,0^{\prime \prime}$ & $039^{\circ} 49^{\prime} 41,2^{\prime \prime}$ & $12 / 05 / 2002$ & oblíquo & $1.000 \mathrm{~m}$ & cilíndrico-cônica & 500 & 1 \\
\hline 5547 & $22^{\circ} 32^{\prime} 49,0^{\prime \prime}$ & $040^{\circ} 04^{\prime} 20,9^{\prime \prime}$ & 07/11/2001 & oblíquo & $1.000 \mathrm{~m}$ & cilíndrico-cônica & 500 & 4 \\
\hline 7495 & $21^{\circ} 58 ' 31,0^{\prime \prime}$ & $039^{\circ} 50^{\prime} 29,7^{\prime \prime}$ & $10 / 10 / 2001$ & oblíquo & $1.000 \mathrm{~m}$ & cilíndrico-cônica & 500 & 1 \\
\hline 7496 & $21^{\circ} 54^{\prime} 36,5^{\prime \prime}$ & $039^{\circ} 45^{\prime} 20,0^{\prime \prime}$ & $10 / 10 / 2001$ & oblíquo & $1.000 \mathrm{~m}$ & cilíndrico-cônica & 500 & 1 \\
\hline 17623 & $22^{\circ} 31^{\prime} 40,9^{\prime \prime}$ & $040^{\circ} 02^{\prime} 39,6^{\prime \prime}$ & 07/11/2001 & oblíquo & $1.000 \mathrm{~m}$ & cilíndrico-cônica & 500 & 1 \\
\hline 17625 & $22^{\circ} 31^{\prime} 40,9^{\prime \prime}$ & $040^{\circ} 02^{\prime} 39,6^{\prime \prime}$ & $07 / 11 / 2001$ & oblíquo & $1.000 \mathrm{~m}$ & cilíndrico-cônica & 500 & 1 \\
\hline 17626 & $22^{\circ} 31^{\prime} 40,9^{\prime \prime}$ & $040^{\circ} 02^{\prime} 39,6^{\prime \prime}$ & $07 / 11 / 2001$ & oblíquo & $1.000 \mathrm{~m}$ & cilíndrico-cônica & 500 & 4 \\
\hline 17628 & $22^{\circ} 32^{\prime} 49,0^{\prime \prime}$ & $040^{\circ} 04^{\prime} 20,9^{\prime \prime}$ & $07 / 11 / 2001$ & oblíquo & $1.000 \mathrm{~m}$ & cilíndrico-cônica & 500 & 2 \\
\hline
\end{tabular}

Referências: Johnson, 1974; Osawa, 1986; Bonecker et al., 2006b; Ditty, 2006a; Fahay, 2007. 


\section{Família Notosudidae}

A família Notosudidae é marinha e mesopelágica. Ocorre desde a região subártica até a subantártica. Compreende três gêneros com 19 espécies. As larvas possuem o corpo alongado e fino, com focinho longo e pontudo. Os olhos são estreitos com uma massa cônica de tecido coroide prolongada na região posterior; são um pouco pedunculados nas larvas menores. Presença de nadadeira adiposa. Na maioria das espécies o intestino é curto, alcançando aproximadamente a metade do corpo. A pigmentação ocorre primeiramente na região da cauda e é a principal característica para a identificação das espécies. Algumas espécies não possuem pigmentação no corpo e podem ser separadas pelo número de vértebras.

No Brasil já foram identificadas cinco espécies nas fases de larva e adulto: Ahliesaurus berryi Bertelsen, Krefft \& Marshall, 1976; Luciosudis normani Fraser-Brunner, 1931; Scopelosaurus argenteus (Maul, 1954); Scopelosaurus herwigi Bertelsen, Krefft \& Marshall, 1976 e Scopelosaurus smithii Bean, 1925. Nesse estudo são contempladas as espécies Scopelosaurus herwigi e Scopelosaurus smithii. 


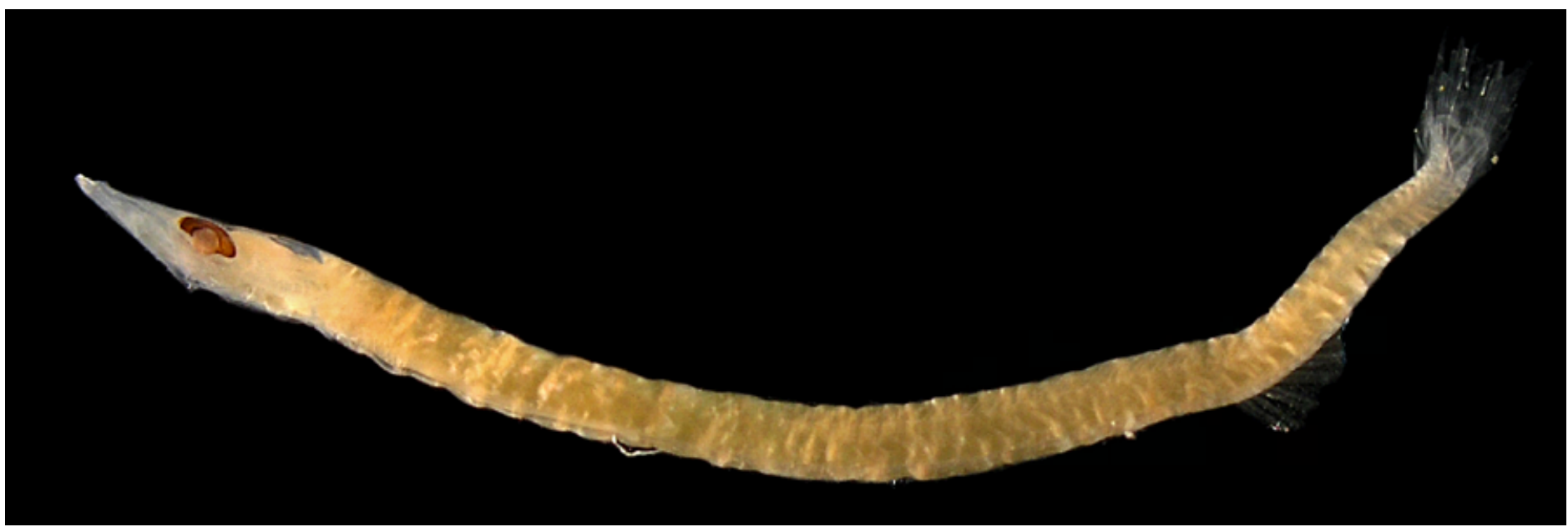

Figura 38: Scopelosaurus herwigi. DZUFRJ 7399; Pós-flexão; CP 22,0 mm.

\section{Scopelosaurus herwigi Bertelsen, Krefft \& Marshall, 1976}

A principal característica da larva dessa espécie é a ausência de pigmentos no corpo. Pode ser separada das demais espécies que também não apresentam pigmento através da contagem do número de vértebras, que nessa espécie varia entre 60 e 62.

Tamanho: flexão 10,5 mm; pós-flexão 22,0-26,0 mm.

Habitat: espécie marinha, bentopelágica, ocorre até 750 m de profundidade.

\section{Georreferenciamento}

\begin{tabular}{|c|c|c|c|c|c|c|c|c|}
\hline DZUFRJ & Latitude (S) & Longitude (W) & Data & $\begin{array}{l}\text { Tipo de } \\
\text { arrasto }\end{array}$ & $\begin{array}{l}\text { Profundidade } \\
\text { de coleta }\end{array}$ & Rede & $\begin{array}{c}\text { Malha } \\
(\mu \mathrm{m})\end{array}$ & $\begin{array}{l}N^{\circ} \text {. de } \\
\text { inds. }\end{array}$ \\
\hline 5385 & $22^{\circ} 31^{\prime} 58,9^{\prime \prime}$ & $040^{\circ} 02^{\prime} 53,4^{\prime \prime}$ & $07 / 11 / 2001$ & oblíquo & $1.000 \mathrm{~m}$ & cilíndrico-cônica & 500 & 1 \\
\hline 5388 & $22^{\circ} 32^{\prime} 50,0^{\prime \prime}$ & $040^{\circ} 04^{\prime} 09,9^{\prime \prime}$ & $06 / 11 / 2001$ & oblíquo & $1.000 \mathrm{~m}$ & cilíndrico-cônica & 500 & 3 \\
\hline 5389 & $22^{\circ} 32^{\prime} 49,0^{\prime \prime}$ & $040^{\circ} 04^{\prime} 20,9^{\prime \prime}$ & $07 / 11 / 2001$ & oblíquo & $0 \mathrm{~m}$ & cilíndrico-cônica & 00 & 2 \\
\hline 5390 & $22^{\circ} 31^{\prime} 40,9^{\prime \prime}$ & $040^{\circ} 02^{\prime} 39,6^{\prime \prime}$ & $07 / 11 / 2001$ & oblíquo & $1.000 \mathrm{~m}$ & cilíndrico-cônica & 500 & 1 \\
\hline 5391 & $22^{\circ} 31^{\prime} 58,9^{\prime \prime}$ & $040^{\circ} 02^{\prime} 53,4^{\prime \prime}$ & $07 / 11 / 2001$ & oblíquo & $1.000 \mathrm{~m}$ & cilíndrico-cônica & 500 & 1 \\
\hline 5392 & $22^{\circ} 31^{\prime} 58,9^{\prime \prime}$ & $040^{\circ} 02^{\prime} 53,4^{\prime \prime}$ & $07 / 11 / 2001$ & oblíquo & 1.0 & cilíndrico-cônica & 500 & 2 \\
\hline 5394 & $22^{\circ} 31^{\prime} 40,9^{\prime \prime}$ & $040^{\circ} 02^{\prime} 39,6^{\prime \prime}$ & $07 / 11 / 2001$ & oblíquo & $1.000 \mathrm{~m}$ & cilíndrico-cônica & 500 & 5 \\
\hline 5395 & $22^{\circ} 32^{\prime} 49,0^{\prime \prime}$ & $040^{\circ} 04^{\prime} 20,9^{\prime \prime}$ & $07 / 11 / 2001$ & oblíquo & $1.000 \mathrm{~m}$ & cilíndrico-cônica & 500 & 1 \\
\hline 7399 & $21^{\circ} 54^{\prime} 36,5^{\prime \prime}$ & $039^{\circ} 45^{\prime} 20,0^{\prime \prime}$ & $10 / 10 / 2001$ & oblíquo & $1.000 \mathrm{~m}$ & cilíndrico-cônica & 500 & 1 \\
\hline 7402 & $21^{\circ} 58^{\prime} 31,0^{\prime \prime}$ & $039^{\circ} 50^{\prime} 29,7^{\prime \prime}$ & $10 / 10 / 2001$ & oblíquo & $1.000 \mathrm{~m}$ & cilíndrico-cônica & 500 & 3 \\
\hline 24180 & $21^{\circ} 54^{\prime} 36,5^{\prime \prime}$ & $039^{\circ} 45^{\prime} 20,0^{\prime \prime}$ & 09/10/2001 & oblíquo & $1.000 \mathrm{~m}$ & cilíndrico-cônica & 500 & 1 \\
\hline 24181 & $22^{\circ} 32^{\prime} 49,0^{\prime \prime}$ & $040^{\circ} 04^{\prime} 20,9^{\prime \prime}$ & $07 / 11 / 2001$ & oblíquo & $1.000 \mathrm{~m}$ & cilíndrico-cônica & 500 & 3 \\
\hline
\end{tabular}

Referências: Bertelsen et al., 1976; Bonecker et al., 2006 b. 


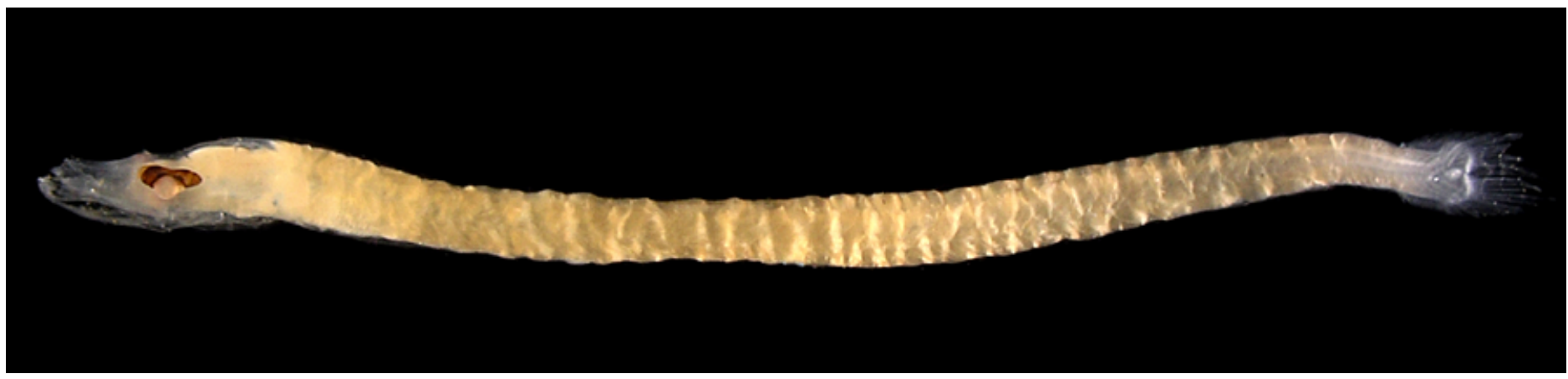

Figura 39 - A: Scopelosaurus smithii. DZUFRJ 7405; Pós-flexão; CP 14,0 mm.

\section{Scopelosaurus smithii Bean, 1925}

Tem corpo alongado e estreito, e o ânus se localiza aproximadamente a 43-45\% do comprimento padrão. A principal característica para a identificação dessa espécie é

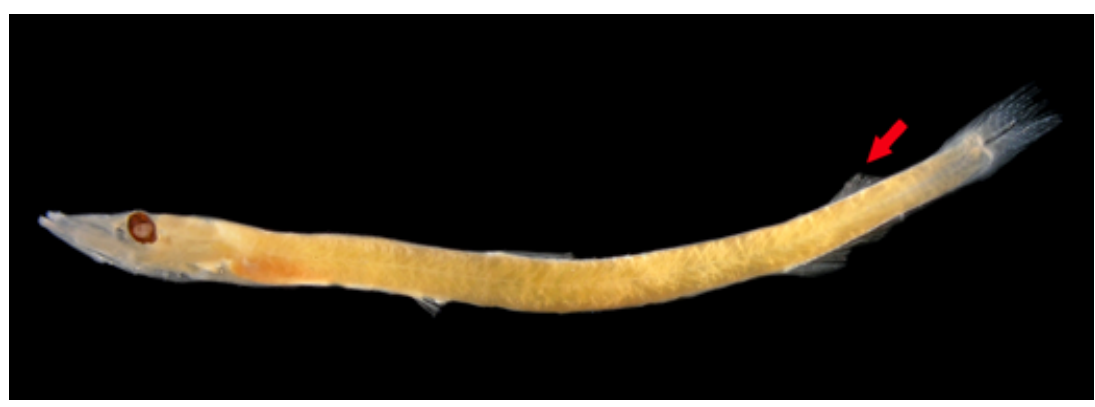

Figura 39 - B: DZUFRJ 7405; Juvenil; CP 31,0 mm. a presença de uma faixa de vários melanóforos pequenos no pedúnculo caudal. Os melanóforos também estão presentes em alguns raios da nadadeira caudal. O número de vértebras nessa espécie varia entre 53 e 56.

Tamanho: pós-flexão 14,0-24,0 mm; juvenil 31,0-33,0 mm.

Habitat: espécie marinha, ocorre em águas tropicais. As larvas são epipelágicas, os juvenis vivem entre 50 e $200 \mathrm{~m}$ de profundidade e os adultos são encontrados em profundidades superiores a $200 \mathrm{~m}$.

\section{Georreferenciamento}

\begin{tabular}{|c|c|c|c|c|c|c|c|c|}
\hline DZUFRJ & Latitude (S) & Longitude (W) & Data & $\begin{array}{l}\text { Tipo de } \\
\text { arrasto }\end{array}$ & $\begin{array}{c}\text { Profundidade } \\
\text { de coleta }\end{array}$ & Rede & $\begin{array}{c}\text { Malha } \\
(\mu \mathrm{m})\end{array}$ & $\begin{array}{l}N^{\circ} \text {. de } \\
\text { inds. }\end{array}$ \\
\hline 1251 & $22^{\circ} 08^{\prime} 17,5^{\prime \prime}$ & $039^{\circ} 46^{\prime} 28,5^{\prime \prime}$ & $11 / 05 / 2002$ & oblíquo & $1.000 \mathrm{~m}$ & cilíndrico-cônica & 500 & 1 \\
\hline 5386 & $22^{\circ} 32^{\prime} 49,0^{\prime \prime}$ & $040^{\circ} 04^{\prime} 20,9^{\prime \prime}$ & $07 / 11 / 2001$ & oblíquo & $1.000 \mathrm{~m}$ & cilíndrico-cônica & 500 & 3 \\
\hline 5387 & $22^{\circ} 32^{\prime} 50,0^{\prime \prime}$ & $040^{\circ} 04^{\prime} 09,9^{\prime \prime}$ & $06 / 11 / 2001$ & oblíquo & $1.000 \mathrm{~m}$ & cilíndrico-cônica & 500 & 1 \\
\hline 5393 & $22^{\circ} 31^{\prime} 40,9^{\prime \prime}$ & $040^{\circ} 02^{\prime} 39,6^{\prime \prime}$ & $07 / 11 / 2001$ & oblíquo & $1.000 \mathrm{~m}$ & cilíndrico-cônica & 500 & 2 \\
\hline 7398 & $21^{\circ} 54^{\prime} 36,5^{\prime \prime}$ & $039^{\circ} 45^{\prime} 20,0^{\prime \prime}$ & 09/10/2001 & oblíquo & $1.000 \mathrm{~m}$ & cilíndrico-cônica & 500 & 2 \\
\hline 7400 & $21^{\circ} 53^{\prime} 10,4^{\prime \prime}$ & $039^{\circ} 45^{\prime} 49,9^{\prime \prime}$ & $10 / 10 / 2001$ & oblíquo & $1.000 \mathrm{~m}$ & cilíndrico-cônica & 500 & 1 \\
\hline 7401 & $21^{\circ} 57^{\prime} 10,5^{\prime \prime}$ & $039^{\circ} 43^{\prime} 33,3^{\prime \prime}$ & 09/10/2001 & oblíquo & $1.000 \mathrm{~m}$ & cilíndrico-cônica & 500 & 2 \\
\hline 7404 & $21^{\circ} 57^{\prime} 10,5^{\prime \prime}$ & $039^{\circ} 43^{\prime} 33,3^{\prime \prime}$ & 09/10/2001 & oblíquo & $1.000 \mathrm{~m}$ & cilíndrico-cônica & 500 & 1 \\
\hline 7405 & $21^{\circ} 58^{\prime} 31,0^{\prime \prime}$ & $039^{\circ} 50^{\prime} 29,7^{\prime \prime}$ & $10 / 10 / 2001$ & oblíquo & $1.000 \mathrm{~m}$ & cilíndrico-cônica & 500 & 6 \\
\hline 7406 & $21^{\circ} 53^{\prime} 10,4^{\prime \prime}$ & $039^{\circ} 45^{\prime} 49,9^{\prime \prime}$ & $10 / 10 / 2001$ & oblíquo & $1.000 \mathrm{~m}$ & cilíndrico-cônica & 500 & 5 \\
\hline 24182 & $22^{\circ} 37^{\prime} 21,9^{\prime \prime}$ & $040^{\circ} 02^{\prime} 42,5^{\prime \prime}$ & $08 / 12 / 2002$ & vertical & $200-500 m$ & cilíndrico-cônica & 200 & 1 \\
\hline
\end{tabular}

Referências: Bertelsen et al., 1976; Bonecker et al., 2006b; Richards, 2006g; Fahay, 2007. 


\section{Família Synodontidae}

A família Synodontidae é marinha e raramente ocorre em águas salobras, estando presente nos oceanos Atlântico, Índico e Pacífico. Compreende quatro gêneros com 57 espécies. O corpo é alongado e circular, possui nadadeira adiposa e as nadadeiras pélvicas são abdominais. As larvas dessa família são facilmente reconhecidas pela presença de seis a 12 manchas escuras de pigmentos peritoneais ao longo do intestino. As espécies podem ser separadas pela posição, tamanho, número e espaçamento desses pigmentos, juntamente com o número de miômeros.

No Brasil já foram identificadas 10 espécies nas fases de larva e adulto. Nesse estudo são contempladas as espécies Saurida sp., Synodus synodus e Trachinocephalus myops. 


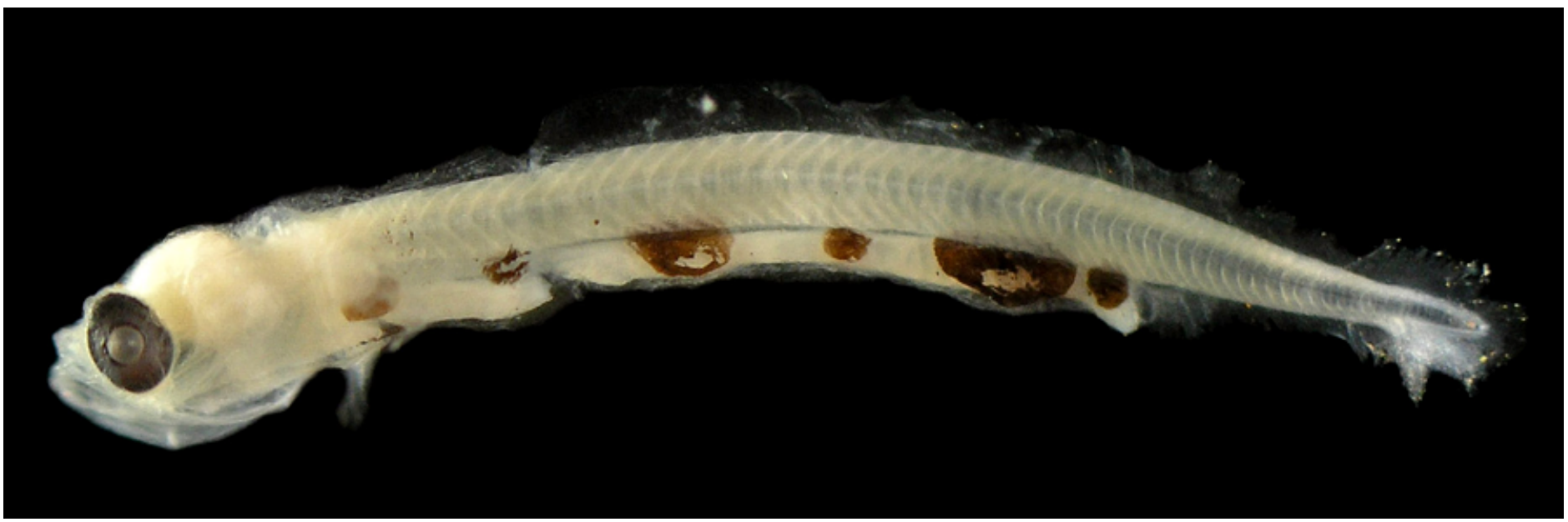

Figura 40 - A: Saurida sp. DZUFRJ 33544; Pré-flexão; CP 5,5 mm.

\section{Saurida}

\section{sp.}

Todas as larvas de Saurida apresentam seis manchas de pigmentos ao longo do intestino; o quinto pigmento é ovalado e maior. Dependendo da espécie, o número

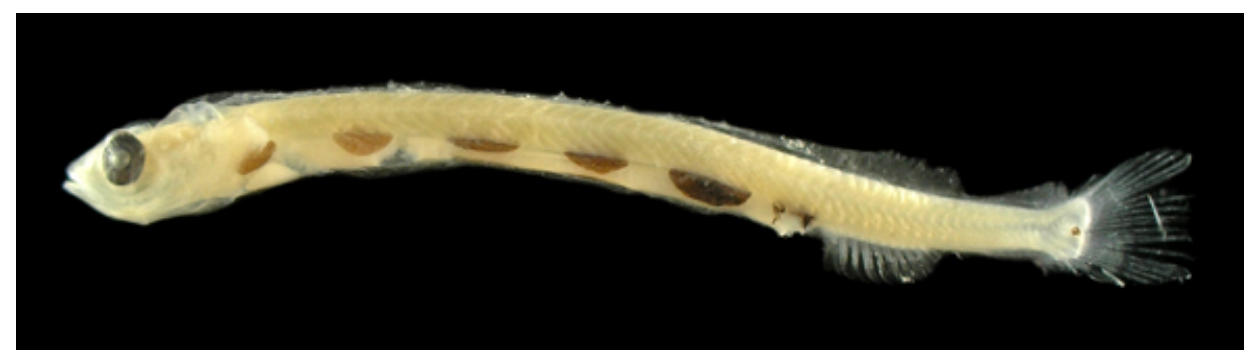

Figura 40 - B: DZUFRJ 33545; Flexão; CP 11,5 mm.

de pigmentos pós-anais pode variar. Os espécimes coletados no presente estudo apresentam um pigmento sobre a base da nadadeira anal e outro posterior a essa nadadeira. O número de miômeros varia aproximadamente entre 45 e 55. No Brasil já foram registradas as espécies Saurida brasiliensis Norman, 1935 e Saurida caribbaea Breder,1927.

Nome vulgar: Peixe-lagarto.

Tamanho: pré-flexão 3,8-5,5 mm; flexão 5,2-15,0 mm.

Habitat: todas as espécies de Saurida são marinhas e algumas podem ocorrer em águas salobras. São demersais, algumas espécies associadas a formações coralinas.

\section{Georreferenciamento}

\begin{tabular}{|c|c|c|c|c|c|c|c|c|}
\hline DZUFRJ & Latitude (S) & Longitude (W) & Data & $\begin{array}{l}\text { Tipo de } \\
\text { arrasto }\end{array}$ & $\begin{array}{c}\text { Profundidade } \\
\text { de coleta }\end{array}$ & Rede & $\begin{array}{l}\text { Malha } \\
(\mu \mathrm{m})\end{array}$ & $\begin{array}{l}\mathrm{N}^{\circ} \text {. de } \\
\text { inds. }\end{array}$ \\
\hline 420 & $22^{\circ} 36^{\prime} 54,9^{\prime \prime}$ & $040^{\circ} 09^{\prime} 19,4^{\prime \prime}$ & $16 / 05 / 2002$ & oblíquo & $50 \mathrm{~m}$ & bongô & 330 & 2 \\
\hline 422 & $22^{\circ} 41^{\prime} 54,7 "$ & $040^{\circ} 14^{\prime} 04,5^{\prime \prime}$ & $16 / 05 / 2002$ & oblíquo & $1.000 \mathrm{~m}$ & cilíndrico-cônica & 500 & 1 \\
\hline 7445 & $21^{\circ} 57^{\prime} 10,5^{\prime \prime}$ & $039^{\circ} 43^{\prime} 33,3^{\prime \prime}$ & 09/10/2001 & oblíquo & $1.000 \mathrm{~m}$ & cilíndrico-cônica & 500 & 1 \\
\hline 7450 & $21^{\circ} 57^{\prime} 10,5^{\prime \prime}$ & $039^{\circ} 43^{\prime} 33,3^{\prime \prime}$ & 09/10/2001 & oblíquo & $1.000 \mathrm{~m}$ & cilíndrico-cônica & 500 & 1 \\
\hline
\end{tabular}

Referências: Bonecker et al., 2006b; Ditty et al., 2006a. 


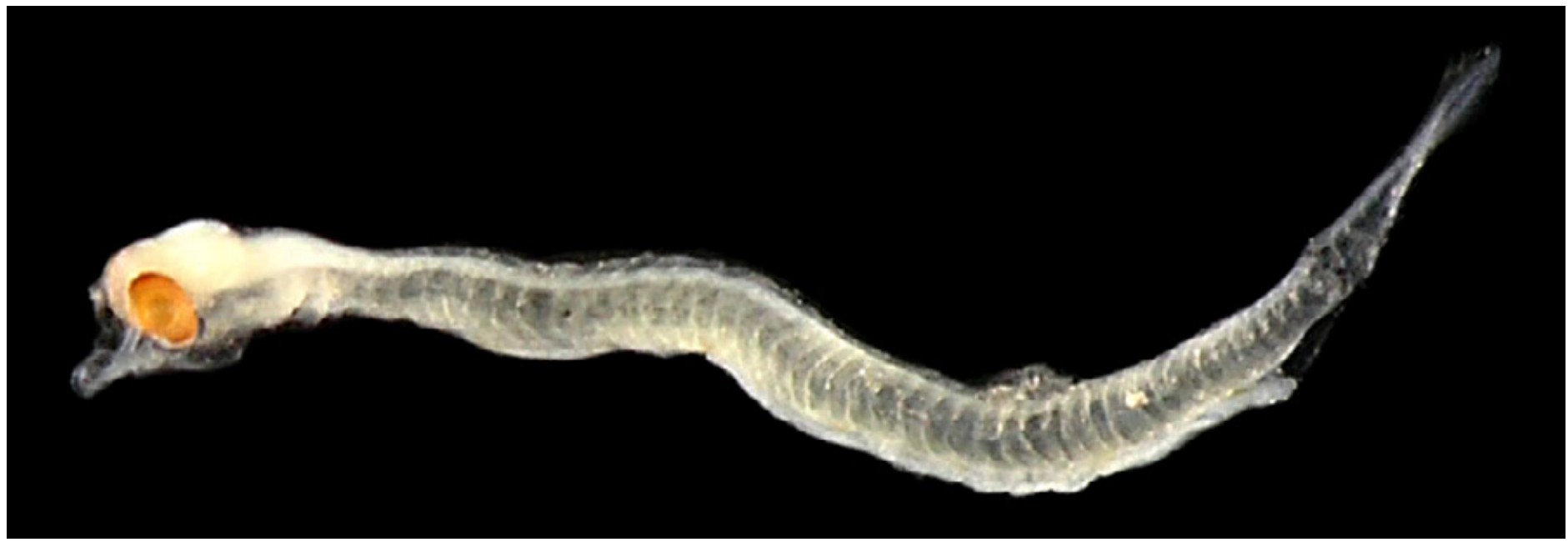

Figura 41 - A: Synodus synodus. DZUFRJ 22080; Pré-flexão; CP 4,5 mm.

\section{Synodus synodus (Linnaeus, 1758)}

Possui o corpo muito alongado e estreito. Apresenta entre doze e treze manchas de pigmentos ao longo do intestino, uma no final da base da nadadeira anal e uma na cauda entre os ossos hipurais. Os pigmentos estão visíveis desde a pré-flexão. O número de miômeros varia aproximadamente entre 56 e 58.

Tamanho: pré-flexão 4,5 mm; flexão 13,9-19,5 mm; pós-flexão 23,3 mm.

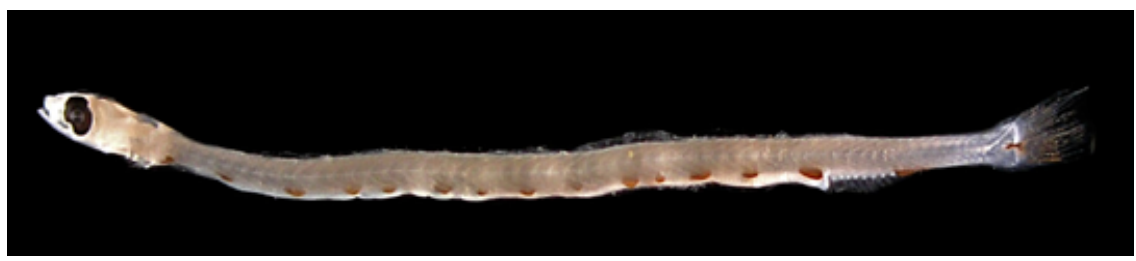

Figura 41 - B: DZUFRJ 12203; Flexão; CP 15,5 mm.

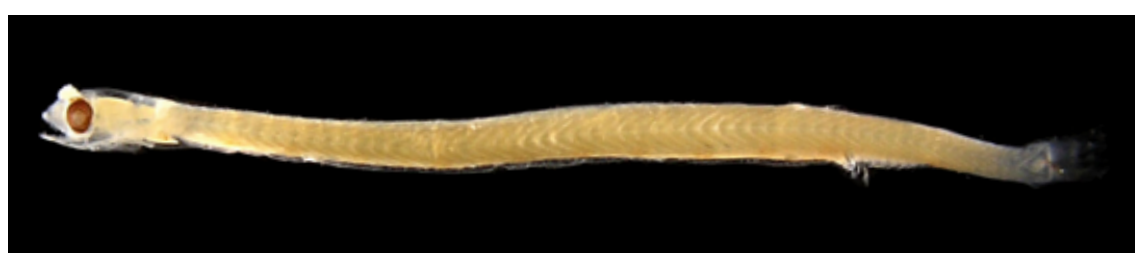

Figura 41 - C: DZUFRJ 1170; Pós-flexão; CP 23,3 mm.

Habitat: espécie marinha, demersal, associada a formações coralinas, ocorre em águas tropicais e subtropicais até $90 \mathrm{~m}$ de profundidade.

Nome vulgar: Peixe-lagarto.

\section{Georreferenciamento}

\begin{tabular}{|c|c|c|c|c|c|c|c|c|}
\hline DZUFRJ & Latitude (S) & Longitude (W) & Data & $\begin{array}{l}\text { Tipo de } \\
\text { arrasto }\end{array}$ & $\begin{array}{l}\text { Profundidade } \\
\text { de coleta }\end{array}$ & Rede & $\begin{array}{c}\text { Malha } \\
(\mu \mathrm{m})\end{array}$ & $\begin{array}{l}\text { No. de } \\
\text { inds. }\end{array}$ \\
\hline 526 & 2 & $039^{\circ} 43^{\prime} 33,3^{\prime \prime}$ & $09 /$ & oblíquo & $1.000 \mathrm{~m}$ & cilíndri & 500 & 2 \\
\hline 1170 & 2502ว'190" & $040^{\circ}$ & $07 / 11 / 2001$ & oblíquo & $1.000 \mathrm{~m}$ & cilíndrico-cônica & 500 & 1 \\
\hline 7446 & $53 ' 10,4 "$ & $039^{\circ} 45^{\prime} 49,9^{\prime \prime}$ & $10 / 10 / 2001$ & oblíquo & $\mathrm{m}$ & cilínd & 500 & 1 \\
\hline 7449 & $53^{\prime} 10,4^{\prime \prime}$ & $039^{\circ} 45^{\prime} 49,9^{\prime \prime}$ & 10 & & $\mathrm{~m}$ & inica & 0 & 1 \\
\hline 7451 & $21^{\circ} 54^{\prime} 36,5^{\prime \prime}$ & $039^{\circ} 45^{\prime} 20,0^{\prime \prime}$ & 10/10/2001 & oblíquo & $1.000 \mathrm{~m}$ & cilíndrico-cônica & 500 & 1 \\
\hline 22080 & $22^{\circ} 41^{\prime} 54,7^{\prime \prime}$ & $040^{\circ} 14^{\prime} 04,5^{\prime \prime}$ & $16 / 05 / 2002$ & oblíquo & $1.000 \mathrm{~m}$ & cilíndrico-cônica & 500 & 1 \\
\hline
\end{tabular}

Referências: Bonecker et al., 2006b; Ditty et al., 2006a. 


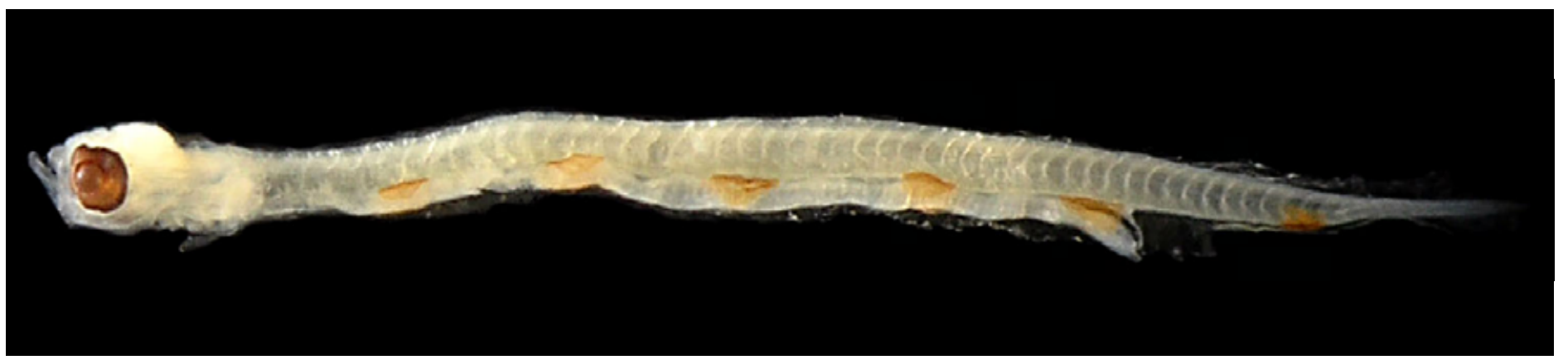

Figura 42: Trachinocephalus myops. DZUFRJ 418; Pré-flexão; CP 7,0 mm.

\section{Trachinocephalus myops (Foster, 1801)}

Apresenta seis manchas de pigmentos ao longo do intestino e uma no final da base da nadadeira anal. As larvas em estágio de pré-flexão possuem pigmentos também nas extremidades dorsal e ventral da cauda. Possui aproximadamente 55 miômeros.

Tamanho: pré-flexão 5,7-8,1 mm.

Habitat: espécie marinha, demersal, associada a formações coralinas, ocorre em águas oceânicas quentes até 387 m de pro-

fundidade.

Nome vulgar: Peixe-lagarto.

Georreferenciamento

\begin{tabular}{|c|c|c|c|c|c|c|c|c|}
\hline DZUFRJ & Latitude (S) & Longitude (W) & Data & $\begin{array}{c}\text { Tipo de } \\
\text { arrasto }\end{array}$ & $\begin{array}{c}\text { Profundidade } \\
\text { de coleta }\end{array}$ & Rede & $\begin{array}{c}\text { Malha } \\
\text { ( } \boldsymbol{\mu m}^{\prime}\end{array}$ & $\begin{array}{c}\mathbf{N}^{\circ} \text {. de } \\
\text { inds. }\end{array}$ \\
\hline 414 & $22^{\circ} 33^{\prime} 47,7^{\prime \prime}$ & $040^{\circ} 12^{\prime} 20,5^{\prime \prime}$ & $17 / 05 / 2002$ & oblíquo & $50 \mathrm{~m}$ & bongô & 330 & 1 \\
\hline 418 & $22^{\circ} 33^{\prime} 37,0^{\prime \prime}$ & $040^{\circ} 19^{\prime} 10,0^{\prime \prime}$ & $17 / 05 / 2002$ & oblíquo & $50 \mathrm{~m}$ & bongô & 500 & 1 \\
\hline 424 & $22^{\circ} 34^{\prime} 05,0^{\prime \prime}$ & $040^{\circ} 19^{\prime} 40,0^{\prime \prime}$ & $17 / 05 / 2002$ & oblíquo & $600 \mathrm{~m}$ & cilíndrico-cônica & 500 & 1 \\
\hline
\end{tabular}

Referências: Bonecker et al., 2006b; Ditty et al., 2006a. 


\section{Família Paralepididae}

A família Paralepididae ocorre em todos os oceanos incluindo o Ártico e a Antártica. Compreende 12 gêneros com aproximadamente 55 espécies. As larvas possuem corpo alongado e estreito, com exceção do gênero Sudis que possui cabeça grande e corpo curto. O número de pigmentos peritoneais e o padrão de pigmentação no corpo, especialmente do pedúnculo caudal, são características muito importantes para a identificação das espécies.

No Brasil já foram identificadas 18 espécies nas fases de larva e adulto. Nesse estudo são contempladas as espécies Lestidiops affinis, Lestidium atlanticum, Lestrolepis intermedia, Magnisudis atlantica, Stemonosudis rothschildi, Stemonosudis sp., Sudis atrox e Uncisudis advena. A espécie S. rothschildi é nova ocorrência para a costa brasileira. 


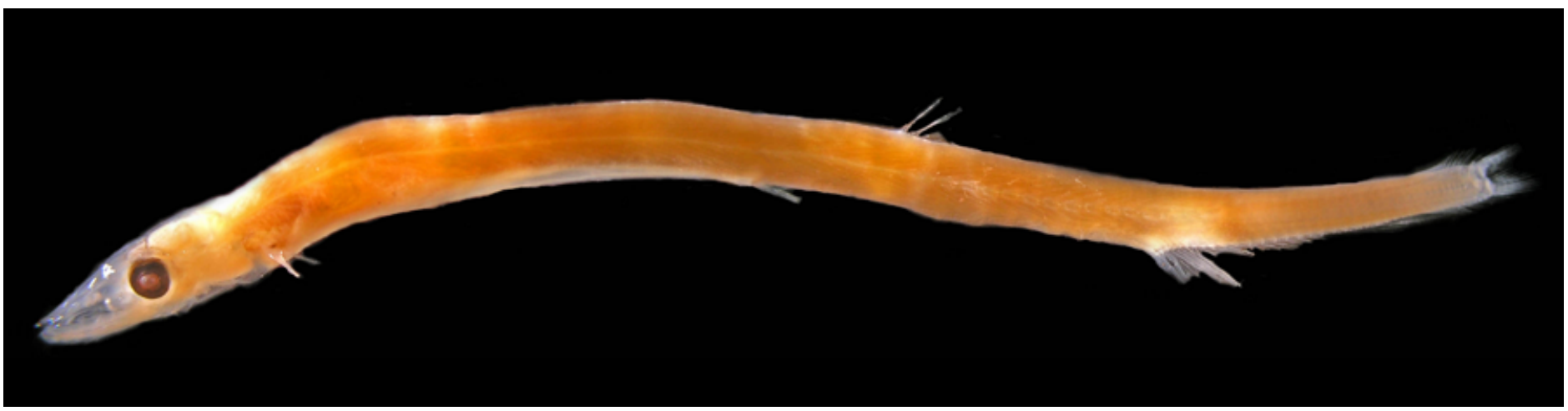

Figura 43: Lestidiops affinis. DZUFRJ 7469; Transformação; CP 48,5 mm.

\section{Lestidiops affinis (Ege, 1930)}

A principal característica das larvas dessa espécie é a presença de pares de pigmentos muito separados na margem ventral do corpo. À medida que a larva cresce aumenta o número de pigmentos na região entre o ânus e o início da nadadeira anal. Durante os estágios de pré-flexão e flexão pode ter até três pigmentos peritoneais ou nenhum. Na pós-flexão tem entre oito e nove manchas de pigmentos peritoneais. No estágio de transformação o número de pigmentos peritoneais aumenta para 11 ou 12. As larvas com mais de $35 \mathrm{~mm}$ CP apresentam pigmentos no focinho, uma série oblíqua abaixo da órbita e duas linhas no pedúnculo. O número de miômeros varia entre 75 e 85.

Tamanho: transformação 48,5 mm.

Habitat: espécie marinha, mesopelágica e batipelágica, ocorre em águas tropicais e temperadas em profundidades de até $2.000 \mathrm{~m}$, normalmente inferior a $600 \mathrm{~m}$. As larvas e os juvenis vivem em profundidades inferiores a $200 \mathrm{~m}$.

\section{Georreferenciamento}

\begin{tabular}{|c|c|c|c|c|c|c|c|c|}
\hline DZUFR & Latitude (S) & Longitude (W) & Data & $\begin{array}{c}\text { Tipo de } \\
\text { arrasto }\end{array}$ & $\begin{array}{c}\text { Profundidade } \\
\text { de coleta }\end{array}$ & Rede & $\begin{array}{c}\text { Malha } \\
(\boldsymbol{\mu m})\end{array}$ & $\begin{array}{c}\mathbf{N}^{\circ} \text {. de } \\
\text { inds. }\end{array}$ \\
\hline 7469 & $21^{\circ} 58^{\prime} 31,0^{\prime \prime}$ & $039^{\circ} 50^{\prime} 29,7^{\prime \prime}$ & $10 / 10 / 2001$ & oblíquo & $1.000 \mathrm{~m}$ & cilíndrico-cônica & 500 & 1 \\
\hline
\end{tabular}

Referências: Rofen, 1966a; Ditty, 2006b; Fahay, 2007. 


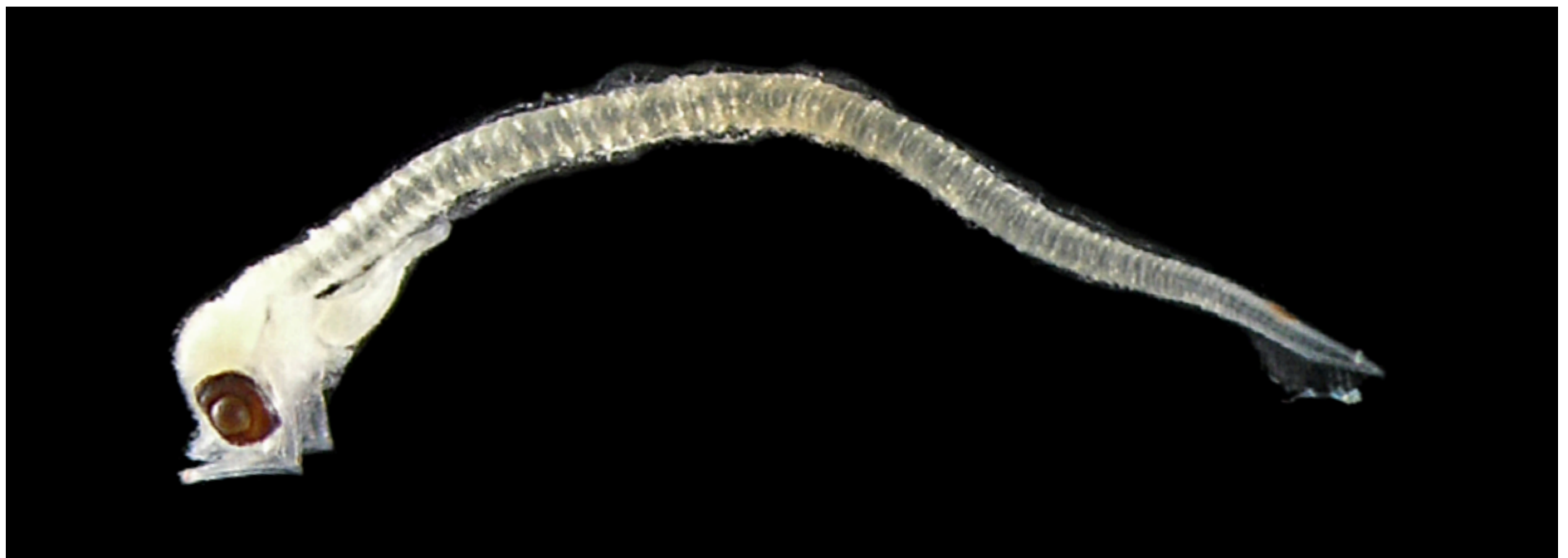

Figura 44 - A: Lestidium atlanticum. DZUFRJ 13222; Pré-flexão; CP 4,3 mm.

\section{Lestidium atlanticum Borodin, 1928}

Possui o corpo fino e alongado (80 a 83 miômeros). A principal característica das larvas com menos de $10 \mathrm{~mm}$ CP é a presença de uma única mancha de pigmento na região dorsal do pedúnculo caudal. Ausência de pigmentos na membrana dos ossos hipurais e na cauda. As larvas em flexão possuem quatro pigmentos peritoneais e começam a aparecer duas linhas de pigmentos no pedúnculo caudal. A mancha na região dorsal do pedúnculo é bem evidente. Em larvas no estágio de pós-flexão começam a aparecer pigmentos na região da cabeça. Nesse estágio, há oito manchas de pigmentos peritoneais e a mancha na região do pedúnculo ainda é evidente. Além da pigmentação da cauda, essa espécie pode ser separada de Lestrolepis e Lestidiops por ter a nadadeira pélvica abaixo da nadadeira dorsal.

Tamanho: pré-flexão 3,5-10,0 mm; flexão 11,0-15,0 mm; pós-flexão 17,3-21,5 $\mathrm{mm}$.

Habitat: espécie marinha, mesopelágica, ocorre em águas tropicais e temperadas quentes em profundidades entre 50 e $1.200 \mathrm{~m}$.

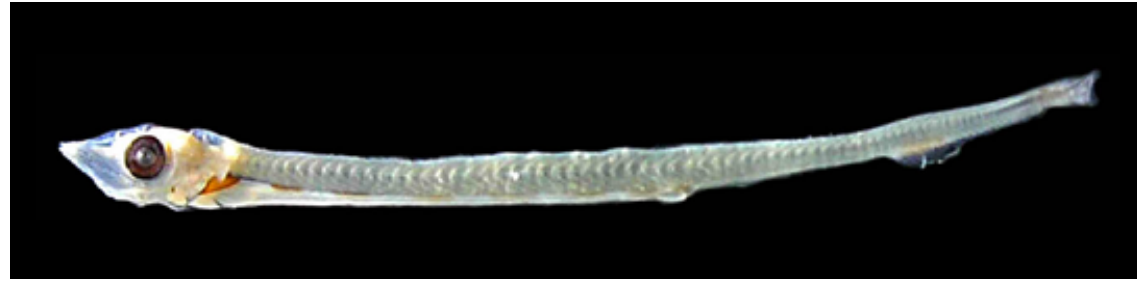

Figura 44 - B: DZUFRJ 11886; Flexão; CP 14,8 mm.

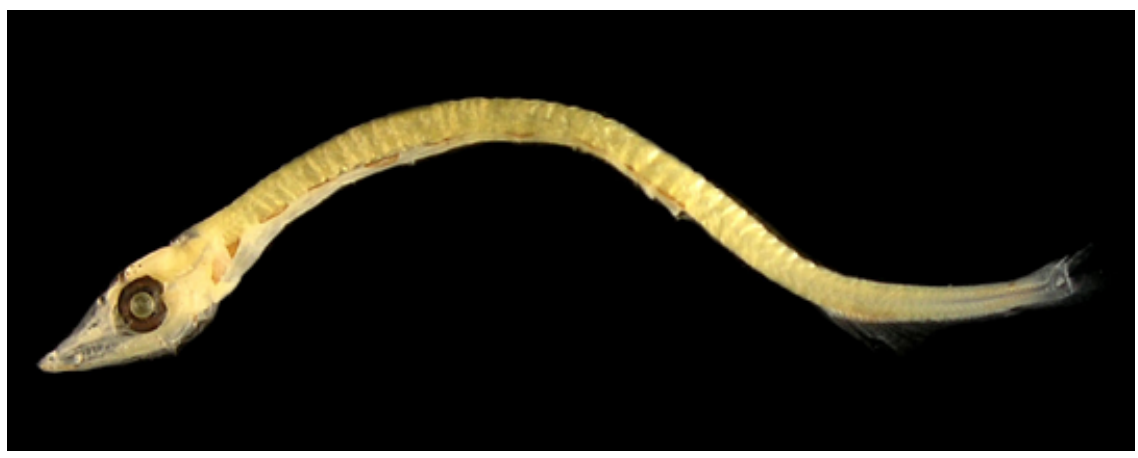

Figura 44 - C: DZUFRJ 13222; Pós-flexão; CP 17,4 mm.

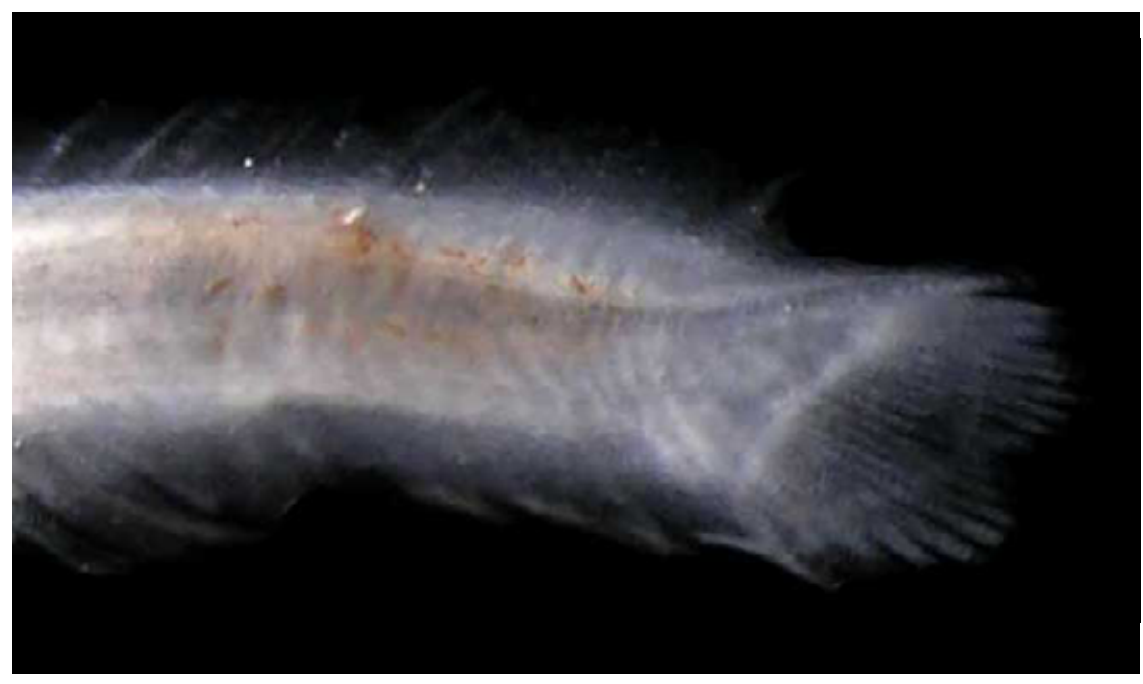

Figura 44 - D: Duas linhas de pigmentos no pedúnculo caudal. 


\section{Georreferenciamento}

\begin{tabular}{|c|c|c|c|c|c|c|c|c|}
\hline DZUFRJ & Latitude (S) & Longitude (W) & Data & $\begin{array}{l}\text { Tipo de } \\
\text { arrasto }\end{array}$ & $\begin{array}{l}\text { Profundidade } \\
\text { de coleta }\end{array}$ & Rede & $\begin{array}{l}\text { Malha } \\
(\mu \mathrm{m})\end{array}$ & $\begin{array}{l}N^{\circ} \text {. de } \\
\text { inds. }\end{array}$ \\
\hline 507 & $22^{\circ} 31^{\prime} 27,0^{\prime \prime}$ & $040^{\circ} 16^{\prime} 56,0^{\prime \prime}$ & $17 / 05 / 2002$ & oblíquo & $600 \mathrm{~m}$ & cilíndrico-cônica & 500 & 1 \\
\hline 560 & $22^{\circ} 32^{\prime} 03,0^{\prime \prime}$ & $040^{\circ} 17^{\prime} 21,0^{\prime \prime}$ & $19 / 05 / 2002$ & oblíquo & $30 \mathrm{~m}$ & bongô & 500 & 4 \\
\hline 584 & $22^{\circ} 33^{\prime} 45,8^{\prime \prime}$ & $040^{\circ} 13^{\prime} 22,9^{\prime \prime}$ & $17 / 05 / 2002$ & oblíquo & $800 \mathrm{~m}$ & cilíndrico-cônica & 500 & 2 \\
\hline 593 & $22^{\circ} 38^{\prime} 29,0^{\prime \prime}$ & $040^{\circ} 17^{\prime} 40,0^{\prime \prime}$ & $18 / 05 / 2002$ & oblíquo & $800 \mathrm{~m}$ & cilíndrico-cônica & 500 & 3 \\
\hline 595 & $22^{\circ} 33^{\prime} 47,7^{\prime \prime}$ & $040^{\circ} 12^{\prime} 20,5^{\prime \prime}$ & $17 / 05 / 2002$ & oblíquo & $50 \mathrm{~m}$ & bongô & 330 & 1 \\
\hline 643 & $22^{\circ} 36^{\prime} 54,9^{\prime \prime}$ & $040^{\circ} 09^{\prime} 19,4^{\prime \prime}$ & $16 / 05 / 2002$ & oblíquo & $50 \mathrm{~m}$ & bongô & 500 & 2 \\
\hline 650 & $22^{\circ} 36^{\prime} 54,9^{\prime \prime}$ & $040^{\circ} 09^{\prime} 19,4^{\prime \prime}$ & $16 / 05 / 2002$ & oblíquo & $50 \mathrm{~m}$ & bongô & 330 & 1 \\
\hline 696 & $22^{\circ} 42^{\prime} 06,0^{\prime \prime}$ & $040^{\circ} 14^{\prime} 26,0^{\prime \prime}$ & $19 / 05 / 2002$ & oblíquo & $50 \mathrm{~m}$ & bongô & 330 & 5 \\
\hline 1183 & $22^{\circ} 07^{\prime} 29,0^{\prime \prime}$ & $039^{\circ} 06^{\prime} 23,5^{\prime \prime}$ & $10 / 05 / 2002$ & oblíquo & $1.000 \mathrm{~m}$ & cilíndrico-cônica & 500 & 3 \\
\hline 1205 & $22^{\circ} 06^{\prime} 52,3^{\prime \prime}$ & $039^{\circ} 48^{\prime} 46,2^{\prime \prime}$ & $11 / 05 / 2002$ & oblíquo & $1.000 \mathrm{~m}$ & cilíndrico-cônica & 500 & 2 \\
\hline 1240 & $22^{\circ} 03^{\prime} 21,7^{\prime \prime}$ & $039^{\circ} 45^{\prime} 11,9^{\prime \prime}$ & $12 / 05 / 2002$ & oblíquo & $1.000 \mathrm{~m}$ & cilíndrico-cônica & 500 & 1 \\
\hline 1293 & $22^{\circ} 02^{\prime} 30,0^{\prime \prime}$ & $039^{\circ} 49^{\prime} 41,2^{\prime \prime}$ & $12 / 05 / 2002$ & oblíquo & até a termoclina & bongô & 500 & 3 \\
\hline 1317 & $22^{\circ} 08^{\prime} 14,9^{\prime \prime}$ & $039^{\circ} 46^{\prime} 34,6^{\prime \prime}$ & $11 / 05 / 2002$ & oblíquo & até a termoclina & bongô & 500 & 1 \\
\hline 1323 & $22^{\circ} 03^{\prime} 03,3^{\prime \prime}$ & $039^{\circ} 50^{\prime} 39,0^{\prime \prime}$ & $10 / 05 / 2002$ & oblíquo & até a termoclina & bongô & 330 & 2 \\
\hline 1343 & $22^{\circ} 06^{\prime} 52,3^{\prime \prime}$ & $039^{\circ} 48^{\prime} 46,2^{\prime \prime}$ & $11 / 05 / 2002$ & oblíquo & até a termoclina & bongô & 330 & 1 \\
\hline 1353 & $22^{\circ} 02^{\prime} 30,0^{\prime \prime}$ & $039^{\circ} 49^{\prime} 41,2^{\prime \prime}$ & $12 / 05 / 2002$ & oblíquo & até a termoclina & bongô & 330 & 2 \\
\hline 5449 & $22^{\circ} 31^{\prime} 58,9^{\prime \prime}$ & $040^{\circ} 02^{\prime} 53,4^{\prime \prime}$ & $07 / 11 / 2001$ & oblíquo & $1.000 \mathrm{~m}$ & cilíndrico-cônica & 500 & 4 \\
\hline 5450 & $22^{\circ} 32^{\prime} 49,0^{\prime \prime}$ & $040^{\circ} 04^{\prime} 20,9^{\prime \prime}$ & $07 / 11 / 2001$ & oblíquo & $1.000 \mathrm{~m}$ & cilíndrico-cônica & 500 & 2 \\
\hline 5451 & $22^{\circ} 32^{\prime} 50,0^{\prime \prime}$ & $040^{\circ} 04^{\prime} 09,9^{\prime \prime}$ & $06 / 11 / 2001$ & oblíquo & $1.000 \mathrm{~m}$ & cilíndrico-cônica & 500 & 3 \\
\hline 5453 & $22^{\circ} 32^{\prime} 49,0^{\prime \prime}$ & $040^{\circ} 04^{\prime} 20,9^{\prime \prime}$ & 07/11/2001 & oblíquo & $1.000 \mathrm{~m}$ & cilíndrico-cônica & 500 & 6 \\
\hline 5455 & $22^{\circ} 32^{\prime} 50,0^{\prime \prime}$ & $040^{\circ} 04^{\prime} 09,9^{\prime \prime}$ & $06 / 11 / 2001$ & oblíquo & $1.000 \mathrm{~m}$ & cilíndrico-cônica & 500 & 3 \\
\hline 5458 & $22^{\circ} 32^{\prime} 49,0^{\prime \prime}$ & $040^{\circ} 04^{\prime} 20,9^{\prime \prime}$ & 07/11/2001 & oblíquo & $1.000 \mathrm{~m}$ & cilíndrico-cônica & 500 & 2 \\
\hline 5459 & $22^{\circ} 31^{\prime} 40,9^{\prime \prime}$ & $040^{\circ} 02^{\prime} 39,6^{\prime \prime}$ & 07/11//2001 & oblíquo & $1.000 \mathrm{~m}$ & cilíndrico-cônica & 500 & 5 \\
\hline 5460 & $22^{\circ} 31^{\prime} 40,9^{\prime \prime}$ & $040^{\circ} 02^{\prime} 39,6^{\prime \prime}$ & $07 / 11 / 2001$ & oblíquo & $1.000 \mathrm{~m}$ & cilíndrico-cônica & 500 & 4 \\
\hline 7452 & $21^{\circ} 54^{\prime} 36,5^{\prime \prime}$ & $039^{\circ} 45^{\prime} 20,0^{\prime \prime}$ & $10 / 10 / 2001$ & oblíquo & $1.000 \mathrm{~m}$ & cilíndrico-cônica & 500 & 4 \\
\hline 7453 & $21^{\circ} 57^{\prime} 10,5^{\prime \prime}$ & $039^{\circ} 43^{\prime} 33,3^{\prime \prime}$ & 09/10/2001 & oblíquo & $1.000 \mathrm{~m}$ & cilíndrico-cônica & 500 & 4 \\
\hline 7454 & $21^{\circ} 57^{\prime} 10,5^{\prime \prime}$ & $039^{\circ} 43^{\prime} 33,3^{\prime \prime}$ & 09/10/2001 & oblíquo & $1.000 \mathrm{~m}$ & cilíndrico-cônica & 500 & 8 \\
\hline 7456 & $21^{\circ} 58^{\prime} 31,0^{\prime \prime}$ & $039^{\circ} 50^{\prime} 29,7^{\prime \prime}$ & $11 / 10 / 2001$ & oblíquo & $1.000 \mathrm{~m}$ & cilíndrico-cônica & 500 & 10 \\
\hline 7461 & $21^{\circ} 58^{\prime} 31,0^{\prime \prime}$ & $039^{\circ} 50^{\prime} 29,7^{\prime \prime}$ & $10 / 10 / 2001$ & oblíquo & $1.000 \mathrm{~m}$ & cilíndrico-cônica & 500 & 7 \\
\hline 7462 & $21^{\circ} 57^{\prime} 10,5^{\prime \prime}$ & $039^{\circ} 43^{\prime} 33,3^{\prime \prime}$ & 09/10/2001 & oblíquo & $1.000 \mathrm{~m}$ & cilíndrico-cônica & 500 & 5 \\
\hline 7463 & $21^{\circ} 53^{\prime} 10,4^{\prime \prime}$ & $039^{\circ} 45^{\prime} 49,9^{\prime \prime}$ & $10 / 10 / 2001$ & oblíquo & $1.000 \mathrm{~m}$ & cilíndrico-cônica & 500 & 2 \\
\hline 7466 & $21^{\circ} 54^{\prime} 36,5^{\prime \prime}$ & $039^{\circ} 45^{\prime} 20,0^{\prime \prime}$ & 09/10/2001 & oblíquo & $1.000 \mathrm{~m}$ & cilíndrico-cônica & 500 & 7 \\
\hline 7468 & $21^{\circ} 53^{\prime} 10,4^{\prime \prime}$ & $039^{\circ} 45^{\prime} 49,9^{\prime \prime}$ & 10/10/2001 & oblíquo & $1.000 \mathrm{~m}$ & cilíndrico-cônica & 500 & 2 \\
\hline 13752 & $21^{\circ} 53^{\prime} 10,4^{\prime \prime}$ & $039^{\circ} 45^{\prime} 49,9^{\prime \prime}$ & 10/10/2001 & oblíquo & $1.000 \mathrm{~m}$ & cilíndrico-cônica & 500 & 1 \\
\hline 13754 & $22^{\circ} 31^{\prime} 58,9^{\prime \prime}$ & $040^{\circ} 02^{\prime} 53,4^{\prime \prime}$ & $07 / 11 / 2001$ & oblíquo & $1.000 \mathrm{~m}$ & cilíndrico-cônica & 500 & 4 \\
\hline 13760 & $22^{\circ} 32^{\prime} 50,0^{\prime \prime}$ & $040^{\circ} 04^{\prime} 09,9^{\prime \prime}$ & 06/11/2001 & oblíquo & $1.000 \mathrm{~m}$ & cilíndrico-cônica & 500 & 2 \\
\hline 13777 & $21^{\circ} 54 ' 36,5^{\prime \prime}$ & $039^{\circ} 45^{\prime} 20,0^{\prime \prime}$ & 10/10/2001 & oblíquo & $1.000 \mathrm{~m}$ & cilíndrico-cônica & 500 & 17 \\
\hline 13786 & $21^{\circ} 58^{\prime} 31,0^{\prime \prime}$ & $039^{\circ} 50^{\prime} 29,7 "$ & 10/10/2001 & oblíquo & $1.000 \mathrm{~m}$ & cilíndrico-cônica & 500 & 7 \\
\hline 13795 & $22^{\circ} 43,56^{\prime}$ & $039^{\circ} 53,25^{\prime}$ & $14 / 06 / 2003$ & vertical & $60 \mathrm{~m}$ & cilíndrico-cônica & 500 & 1 \\
\hline 13797 & $21^{\circ} 57,51^{\prime}$ & $039^{\circ} 49,57^{\prime}$ & $19 / 06 / 2003$ & vertical & $95 \mathrm{~m}$ & cilíndrico-cônica & 500 & 1 \\
\hline 13798 & $22^{\circ} 02,27^{\prime}$ & $039^{\circ} 43,49^{\prime}$ & $18 / 06 / 2003$ & vertical & $90 \mathrm{~m}$ & cilíndrico-cônica & 500 & 1 \\
\hline 14171 & $22^{\circ} 02,2865^{\prime}$ & $039^{\circ} 42,9495^{\prime}$ & $04 / 12 / 2002$ & vertical & $700-1.200 m$ & cilíndrico-cônica & 200 & 1 \\
\hline 18922 & $22^{\circ} 42^{\prime} 06,0^{\prime \prime}$ & $040^{\circ} 14^{\prime} 26,0^{\prime \prime}$ & $19 / 05 / 2002$ & oblíquo & $50 \mathrm{~m}$ & bongô & 500 & 1 \\
\hline 18923 & $22^{\circ} 41^{\prime} 54,7^{\prime \prime}$ & $040^{\circ} 14^{\prime} 04,5^{\prime \prime}$ & $16 / 05 / 2002$ & oblíquo & $1.000 \mathrm{~m}$ & cilíndrico-cônica & 500 & 1 \\
\hline 18924 & $22^{\circ} 32^{\prime} 03,0^{\prime \prime}$ & $040^{\circ} 17^{\prime} 21,0^{\prime \prime}$ & $19 / 05 / 2002$ & oblíquo & $30 \mathrm{~m}$ & bongô & 330 & 5 \\
\hline 18925 & $22^{\circ} 34^{\prime} 05,0^{\prime \prime}$ & $040^{\circ} 19^{\prime} 40,0^{\prime \prime}$ & $17 / 05 / 2002$ & oblíquo & $600 \mathrm{~m}$ & cilíndrico-cônica & 500 & 1 \\
\hline
\end{tabular}

Referências: Rofen, 1966a; Bonecker et al., 2006b; Ditty, 2006b; Fahay, 2007. 


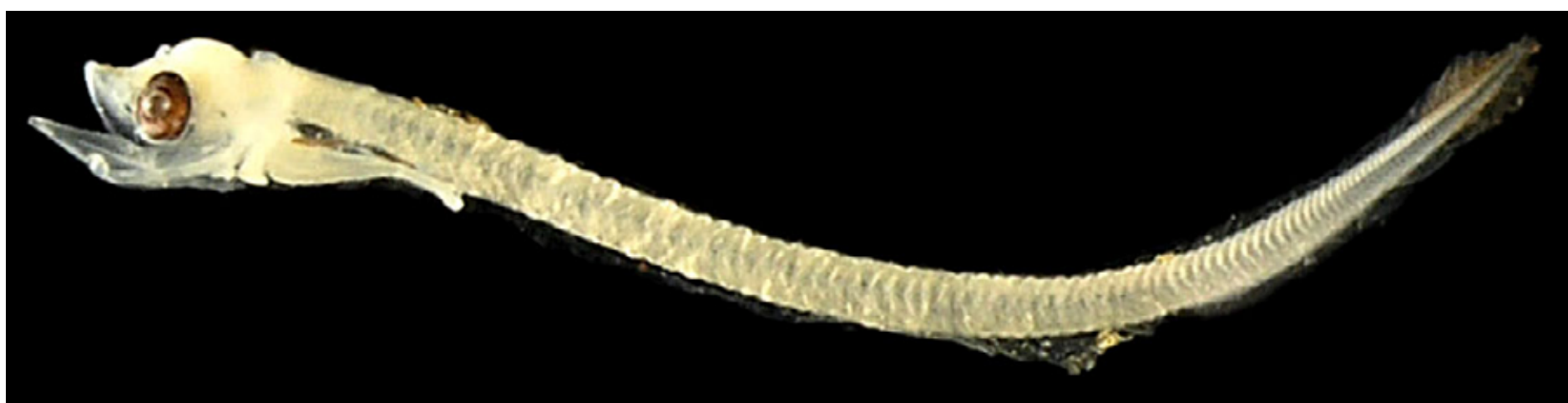

Figura 45 - A: Lestrolepis intermedia. DZUFRJ 15743; Pré-flexão; CP 8,4 mm.

\section{Lestrolepis intermedia (Poey, 1868)}

Nas larvas em estágio de pré-flexão podem ser observados pigmentos nas regiões dorsal e ventral do pedúnculo caudal e na membrana embrionária caudal. No estágio de flexão começam a aparecer quatro linhas paralelas de pigmentos na região do pedúnculo caudal. Em pré-flexão e flexão possui um a sete pigmentos peritoneais. No estágio de pós-flexão possui oito pigmentos peritoneais e um arco no cérebro. A nadadeira pélvica está localizada bem anteriormente a origem da dorsal. O número de miômeros varia entre 91 e 93.

Tamanho: pré-flexão 5,0-8,4 mm; flexão 13,5 mm.

Habitat: espécie marinha, mesopelágica, ocorre em águas tropicais e temperadas quentes em profundidades entre 400 e $1.500 \mathrm{~m}$.

\section{Georreferenciamento}

\begin{tabular}{|c|c|c|c|c|c|c|c|c|}
\hline DZUFRJ & Latitude (S) & Longitude (W) & Data & $\begin{array}{l}\text { Tipo de } \\
\text { arrasto }\end{array}$ & $\begin{array}{l}\text { Profundidade } \\
\text { de coleta }\end{array}$ & Rede & $\begin{array}{c}\text { Malha } \\
(\mu \mathrm{m})\end{array}$ & $\begin{array}{l}N^{\circ} \text {. de } \\
\text { inds. }\end{array}$ \\
\hline 532 & $22^{\circ} 34^{\prime} 05,0^{\prime \prime}$ & $40^{\circ} 19^{\prime} 40,0 "$ & $17 / 05 / 2002$ & oblíquo & $600 \mathrm{~m}$ & cilíndrico-cônica & 500 & 1 \\
\hline 638 & $22^{\circ} 42^{\prime} 06,0^{\prime \prime}$ & $040^{\circ} 14^{\prime} 26,0^{\prime \prime}$ & $19 / 05 / 2002$ & oblíquo & $50 \mathrm{~m}$ & bongô & 500 & 1 \\
\hline 664 & $22^{\circ} 38^{\prime} 25,0^{\prime \prime}$ & $040^{\circ} 17^{\prime} 41,0^{\prime \prime}$ & $19 / 05 / 2002$ & oblíquo & $40 \mathrm{~m}$ & bongô & 330 & 1 \\
\hline 668 & $22^{\circ} 33^{\prime} 45,8^{\prime \prime}$ & $040^{\circ} 13^{\prime} 22,9^{\prime \prime}$ & $17 / 05 / 2002$ & oblíquo & $800 \mathrm{~m}$ & cilíndrico-cônica & 500 & 1 \\
\hline 672 & $22^{\circ} 41^{\prime} 54,7^{\prime \prime}$ & $040^{\circ} 14^{\prime} 04,5^{\prime \prime}$ & $16 / 05 / 2002$ & oblíquo & $1.000 \mathrm{~m}$ & cilíndrico-cônica & 500 & 1 \\
\hline 13750 & $22^{\circ} 06^{\prime} 52,3^{\prime \prime}$ & $039^{\circ} 48^{\prime} 46,2^{\prime \prime}$ & $11 / 05 / 2002$ & oblíquo & até a termoclina & bongô & 330 & 2 \\
\hline 13751 & $21^{\circ} 57^{\prime} 10,5^{\prime \prime}$ & $039^{\circ} 43^{\prime} 33,3^{\prime \prime}$ & 09/10/2001 & oblíquo & $1.000 \mathrm{~m}$ & cilíndrico-cônica & 500 & 1 \\
\hline 13774 & $21^{\circ} 58^{\prime} 31,0^{\prime \prime}$ & $039^{\circ} 50^{\prime} 29,7^{\prime \prime}$ & $10 / 10 / 2001$ & oblíquo & $1.000 \mathrm{~m}$ & cilíndrico-cônica & 500 & 1 \\
\hline 13780 & $22^{\circ} 06^{\prime} 37,8^{\prime \prime}$ & $039^{\circ} 49^{\prime} 44,8^{\prime \prime}$ & $10 /$ & oblíquo & até a termoclina & & 500 & 1 \\
\hline 13794 & $22^{\circ} 39,68^{\prime}$ & $040^{\circ} 03,24^{\prime}$ & $13 / 06 / 2003$ & vertical & $60 \mathrm{~m}$ & cilíndrico-cônica & 500 & 1 \\
\hline 13796 & $22^{\circ} 02,27^{\prime}$ & $039^{\circ} 43,49^{\prime}$ & $18 / 06 / 2003$ & vertical & $90 \mathrm{~m}$ & cilíndrico-cônica & 500 & 1 \\
\hline 18842 & $22^{\circ} 42^{\prime} 06,0^{\prime \prime}$ & $040^{\circ} 14^{\prime} 26,0^{\prime \prime}$ & $19 / 05 / 2002$ & oblíquo & $50 \mathrm{~m}$ & bongô & 330 & 1 \\
\hline 19078 & $22^{\circ} 32^{\prime} 03,0^{\prime \prime}$ & $040^{\circ} 17^{\prime} 21,0^{\prime \prime}$ & $19 / 05 / 2002$ & oblíquo & $30 \mathrm{~m}$ & bongô & 500 & 1 \\
\hline
\end{tabular}

Referências: Rofen, 1966a; Bonecker et al., 2006b; Ditty, 2006b; Fahay, 2007.

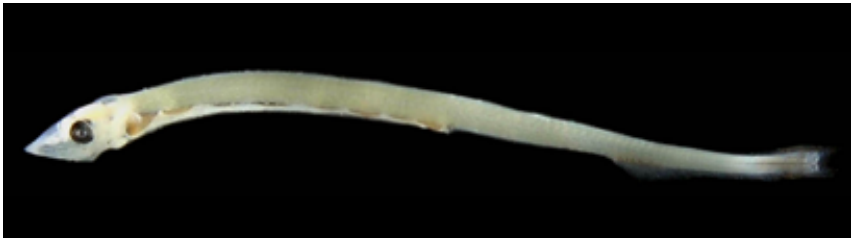

Figura 45 - B: DZUFRJ 12071; Flexão; CP 20,0 mm.

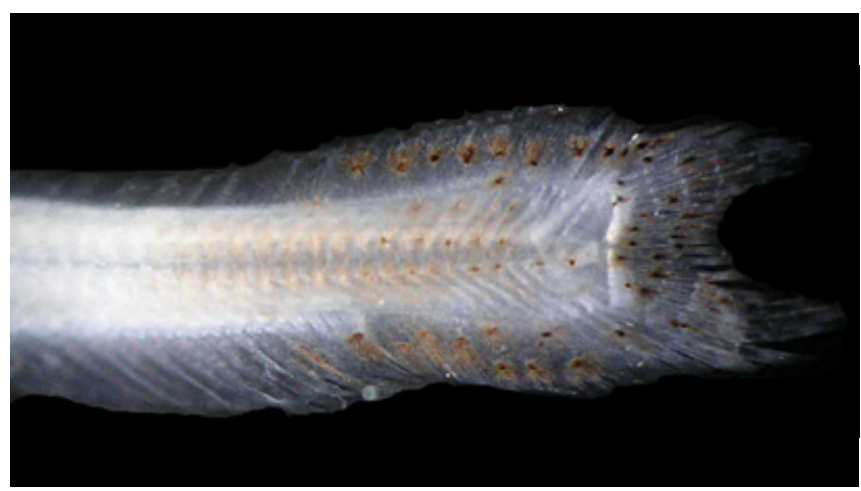

Figura 45 - C: Quatro linhas paralelas de pigmentos na região caudal. 


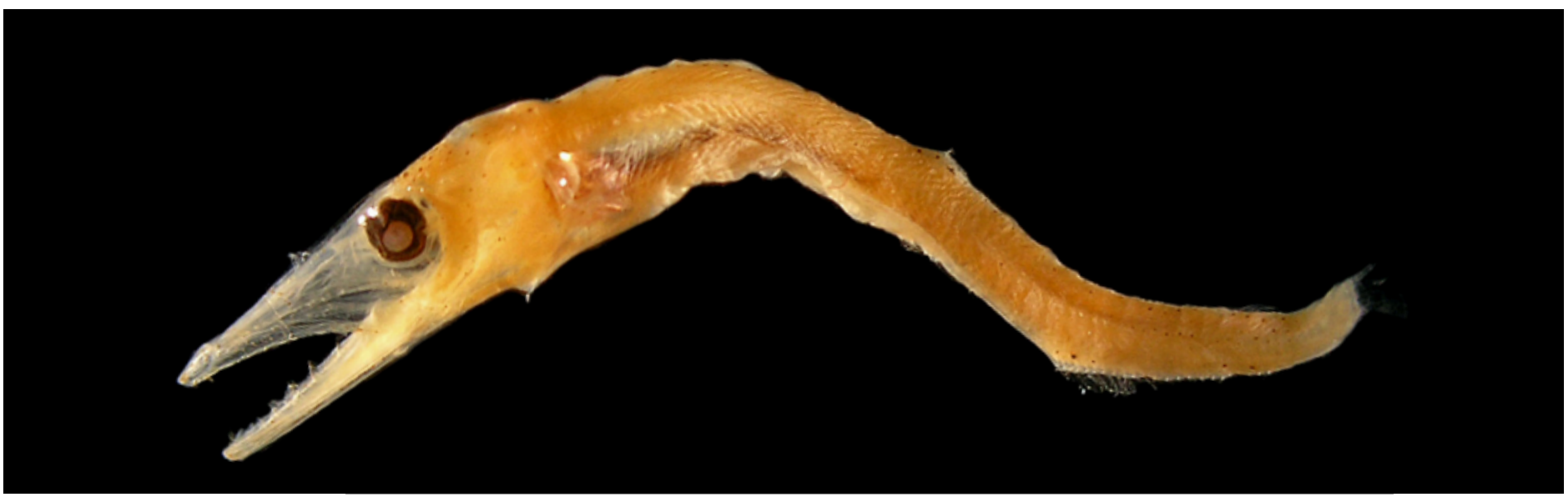

Figura 46 - A: Magnisudis atlantica. DZUFRJ 13775; Pós-flexão; CP 14,1 mm.

\section{Magnisudis atlantica (Krøyer, 1868)}

No estágio de pós-flexão possui pigmentos no focinho, acima dos olhos, na base da nadadeira dorsal e um pigmento acima e

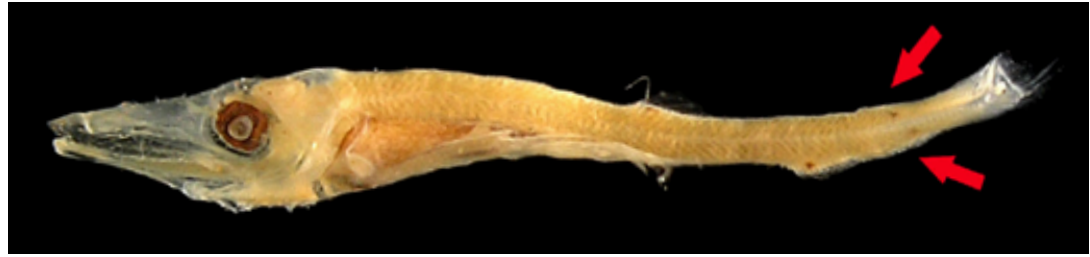

Figura 46 - B: DZUFRJ 13772; Transformação; CP 30,3 mm. abaixo da notocorda no pedúnculo caudal. Os pigmentos acima e abaixo da notocorda aumentam em número até formar uma banda vertical na direção da nadadeira adiposa, em larvas maiores que 19,0 mm CP. Possui de um a três pigmentos peritoneais. Em larvas com 13-15 mm CP o ânus alcança aproximadamente $67-72 \%$ do comprimento padrão. Nos indivíduos em transformação há pigmentos ao longo da região dorsal, na base dos raios da caudal e uma faixa larga na cauda. A nadadeira pélvica se forma abaixo da dorsal. O número de miômeros varia entre 63 e 66.

Tamanho: pós-flexão 14,1 mm; transformação 30,3 mm.

Habitat: espécie marinha, mesopelágica e batipelágica, ocorre em águas tropicais e boreais em profundidades entre 66 e 2.166, principalmente entre 230 e $1.100 \mathrm{~m}$.

\section{Georreferenciamento}

\begin{tabular}{|c|c|c|c|c|c|c|c|c|}
\hline DZUFRJ & Latitude (S) & Longitude (W) & Data & $\begin{array}{l}\text { Tipo de } \\
\text { arrasto }\end{array}$ & $\begin{array}{l}\text { Profundidade } \\
\text { de coleta }\end{array}$ & Rede & $\begin{array}{c}\text { Malha } \\
(\mu \mathrm{m})\end{array}$ & $\begin{array}{l}\text { No. de } \\
\text { inds. }\end{array}$ \\
\hline 13772 & $21^{\circ} 53^{\prime} 10,4^{\prime \prime}$ & $039^{\circ} 45^{\prime} 49,9^{\prime \prime}$ & $10 / 10 / 2001$ & oblíquo & $1.000 \mathrm{~m}$ & cilíndric & 500 & 1 \\
\hline 13773 & $21^{\circ} 58^{\prime} 31,0^{\prime \prime}$ & $039^{\circ} 50^{\prime 29,7 "}$ & $10 / 10 / 2001$ & oblíquo & $1.000 \mathrm{~m}$ & cilíndrico-cônica & 500 & 1 \\
\hline 13775 & $21^{\circ} 53^{\prime} 10,4^{\prime \prime}$ & $039^{\circ} 45^{\prime} 49,9^{\prime \prime}$ & $10 / 10 / 2001$ & oblíquo & $1.000 \mathrm{~m}$ & cilíndrico-cônica & 500 & 1 \\
\hline
\end{tabular}

Referências: Ditty, 2006b; Fahay, 2007. 


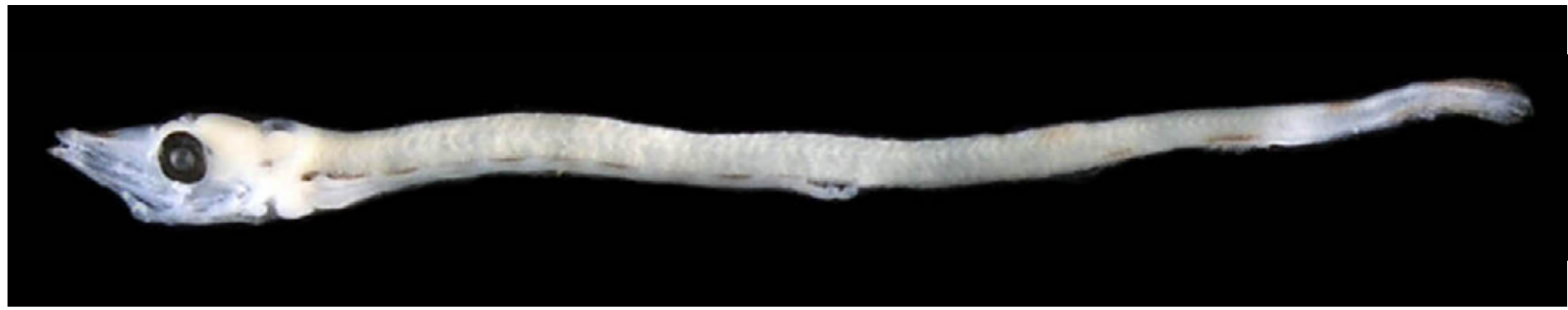

Figura 47 - A: Stemonosudis sp. DZUFRJ 12185; Pré-flexão; CP 10,7 mm.

\section{Stemonosudis}

sp.

As larvas de Stemonosudis apresentam corpo e focinho muito alongados (84 a 121 vértebras). Possuem grupos de pigmentos dorsais e ventrais alternados, e pigmentos no focinho e na cabeça. A na-

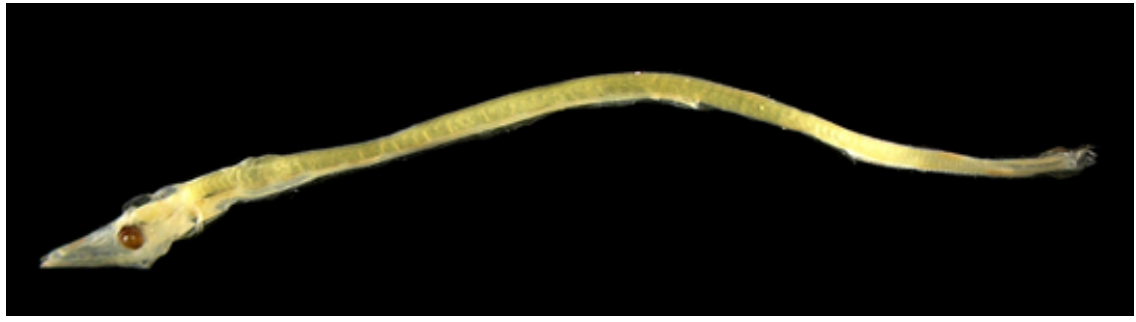

Figura 47 - B: DZUFRJ 13762; Flexão; CP 22,8 mm. dadeira pélvica está situada à frente da origem da nadadeira dorsal. Possuem entre 14 e 18 pigmentos peritoneais. Entre as espécies de Stemonosudis que ocorrem no Brasil, S. rothschildi possui menos pigmentos peritoneais e tem nadadeira dorsal precoce em comparação com S. intermedia e S. siliquiventer. Na literatura, não há descrição da larva de S. siliquiventer e portanto, não foi possível chegar ao nível específico. No Brasil já foram coletadas as espécies Stemonosudis intermedia (Ege, 1933) e Stemonosudis siliquiventer Post, 1970.

Tamanho: pré-flexão 6,4-10,7 mm; flexão 12,5-25,9 mm.

Habitat: as espécies de Stemonosudis são marinhas e batipelágicas, ocorrem em profundidades de até $2.000 \mathrm{~m}$.

\section{Georreferenciamento}

\begin{tabular}{|c|c|c|c|c|c|c|c|c|}
\hline DZUFRJ & Latitude (S) & Longitude (W) & Data & $\begin{array}{l}\text { Tipo de } \\
\text { arrasto }\end{array}$ & $\begin{array}{l}\text { Profundidade } \\
\text { de coleta }\end{array}$ & Rede & $\begin{array}{c}\text { Malha } \\
(\mu \mathrm{m})\end{array}$ & $\begin{array}{l}N^{\circ} \text {. de } \\
\text { inds. }\end{array}$ \\
\hline 1215 & $22^{\circ} 02^{\prime} 30,0^{\prime \prime}$ & $039^{\circ} 49^{\prime} 41,2^{\prime \prime}$ & $12 / 05 / 2002$ & oblíquo & $1.000 \mathrm{~m}$ & cilíndrico-cônica & 500 & 2 \\
\hline 13759 & $22^{\circ} 02^{\prime} 30,0^{\prime \prime}$ & $039^{\circ} 49^{\prime} 41,2^{\prime \prime}$ & $12 / 05 / 2002$ & oblíquo & até a termoclina & bongô & 500 & 1 \\
\hline 13761 & $22^{\circ} 31^{\prime} 40,9^{\prime \prime}$ & $040^{\circ} 02^{\prime} 39,6^{\prime \prime}$ & $07 / 11 / 2001$ & oblíquo & $1.000 \mathrm{~m}$ & cilíndrico-cônica & 500 & 1 \\
\hline 13762 & $22^{\circ} 02^{\prime} 30,0^{\prime \prime}$ & $039^{\circ} 49^{\prime} 41,2^{\prime \prime}$ & $12 / 05 / 2002$ & oblíquo & até a termoclina & bongô & 330 & 2 \\
\hline 13764 & $21^{\circ} 57^{\prime} 10,5^{\prime \prime}$ & $039^{\circ} 43^{\prime} 33,3^{\prime \prime}$ & 09/10/2001 & oblíquo & $1.000 \mathrm{~m}$ & cilíndrico-cônica & 500 & 1 \\
\hline 13785 & $21^{\circ} 58^{\prime} 31,0^{\prime \prime}$ & $039^{\circ} 50^{\prime} 29,7^{\prime \prime}$ & 10/10/2001 & oblíquo & $1.000 \mathrm{~m}$ & cilíndrico-cônica & 500 & 1 \\
\hline
\end{tabular}

Referências: Rofen, 1966a; Bonecker et al., 2006b; Ditty, 2006b; Fahay, 2007. 


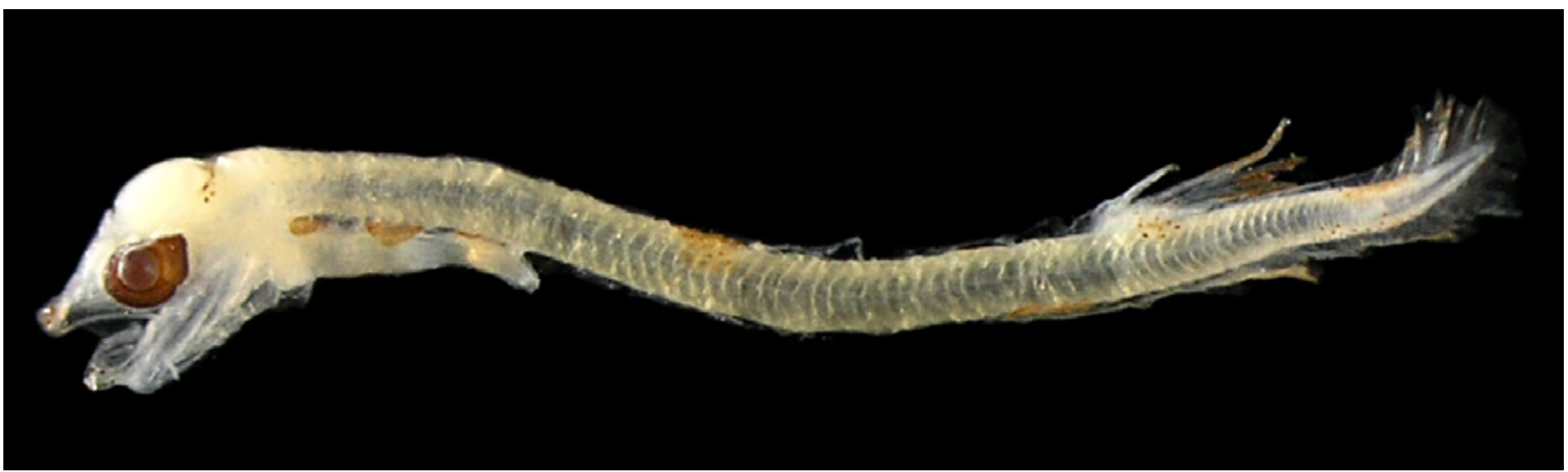

Figura 48: Stemonosudis rothschildi. DZUFRJ 13793; Pré-flexão; CP 5,2 mm.

\section{Stemonosudis rothschildi Richards, 1967}

A principal característica dessa espécie é que os raios da nadadeira dorsal são precoces. Durante o estágio de pré-flexão possui cinco grupos de pigmentos na margem dorsal e dois na margem ventral. Tem pigmentos na ponta do focinho, na região dorsal da cabeça. As larvas com menos de 7,0 mm CP tem três manchas peritoneais. O número de miômeros varia entre 92 e 95.

Tamanho: pré-flexão 6,0 mm.

Habitat: espécie marinha, mesopelágica e batipelágica, ocorre em profundidades entre 30 e $2.250 \mathrm{~m}$.

\section{Georreferenciamento}

\begin{tabular}{|c|c|c|c|c|c|c|c|c|}
\hline DZUFRJ & Latitude (S) & Longitude (W) & Data & $\begin{array}{c}\text { Tipo de } \\
\text { arrasto }\end{array}$ & $\begin{array}{c}\text { Profundidade } \\
\text { de coleta }\end{array}$ & Rede & $\begin{array}{c}\text { Malha } \\
(\boldsymbol{\mu} \text { m) }\end{array}$ & $\begin{array}{c}\text { No. de } \\
\text { inds. }\end{array}$ \\
\hline 13783 & $21^{\circ} 58^{\prime} 31,0^{\prime \prime}$ & $039^{\circ} 50^{\prime} 29,7^{\prime \prime}$ & $11 / 10 / 2001$ & oblíquo & $1.000 \mathrm{~m}$ & cilíndrico-cônica & 500 & 1 \\
\hline
\end{tabular}

Referências: Ditty, 2006b; Fahay, 2007. 


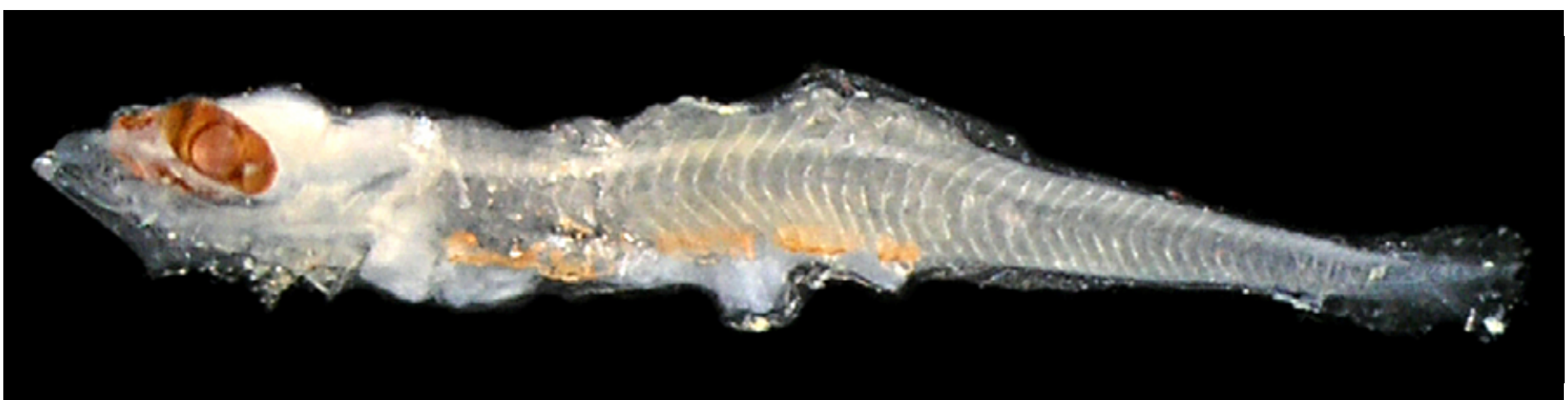

Figura 49 - A: Sudis atrox. DZUFRJ 7149; Pré-flexão; CP 4,9 mm.

\section{Sudis atrox Rofen, 1963}

Nos estágios de pré-flexão e flexão apresenta olho elíptico e o ânus situado na região mediana do corpo. Tem três espinhos pré-operculares grandes, cristas serrilhadas na cabeça, na mandíbula e no focinho. No estágio de pós-flexão, o maior espinho do pré-opérculo possui as extremidades serrilhadas e ganchos. O número de pigmentos peritoneais (três a seis) varia de acordo com o estágio de desenvolvimento larval. Em pós-flexão, apresenta pigmentos na extremidade do focinho, no espinho pré-opercular e no pedúnculo caudal. A nadadeira pélvica está situada na mesma direção da origem da nadadeira dorsal. O número de miômeros varia entre 50 e 55.

Tamanho: pré-flexão 4,1-4,9 mm; flexão 5,39,0 mm; pós-flexão 14,5 mm.

Habitat: espécie marinha, mesopelágica e batipelágica, ocorre em profundidades entre 30 e $2.250 \mathrm{~m}$.

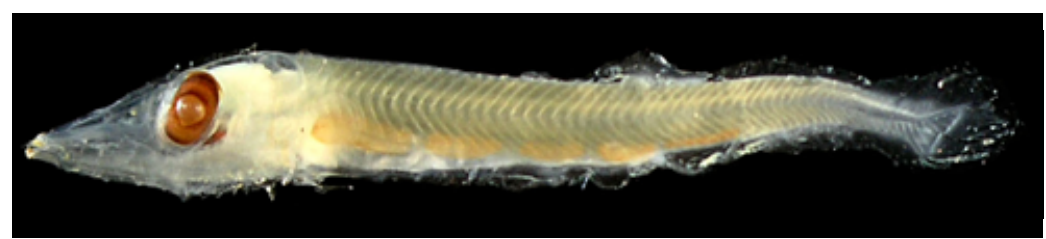

Figura 49 - B: DZUFRJ 7149; Flexão; CP 9,0 mm.

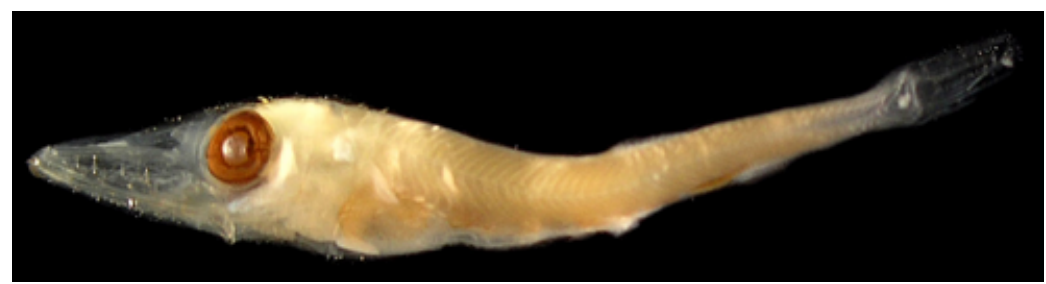

Figura 49 - C: DZUFRJ 7467; Pós-flexão; CP 14,5 mm;

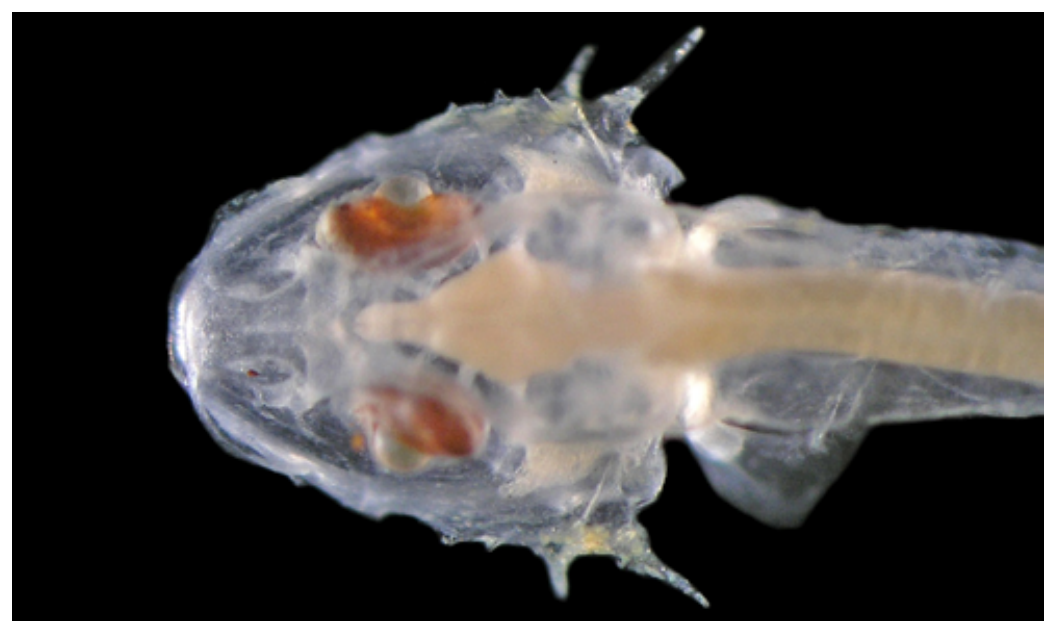

Figura 49 - D: Detalhe da cabeça durante a pré-flexão;

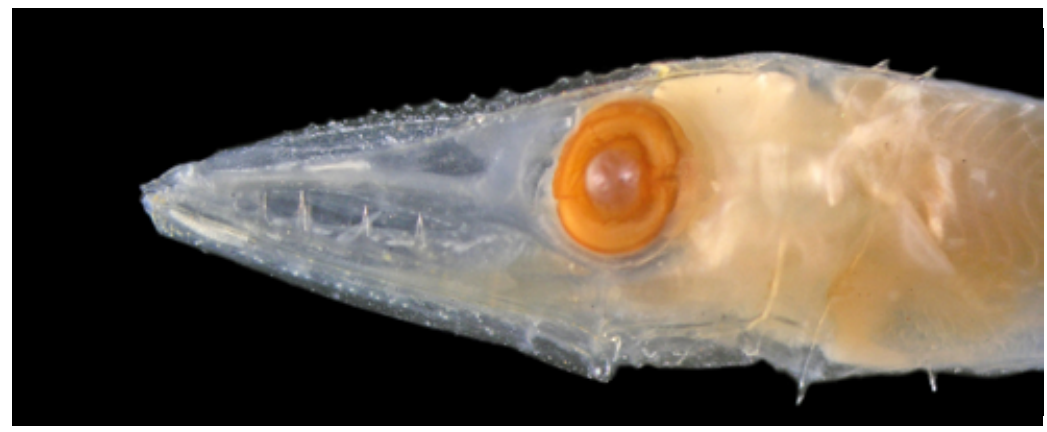

Figura 49 - E: Detalhe da cabeça durante a pós-flexão. 


\section{Georreferenciamento}

\begin{tabular}{|c|c|c|c|c|c|c|c|c|}
\hline DZUFRJ & Latitude (S) & Longitude (W) & Data & $\begin{array}{l}\text { Tipo de } \\
\text { arrasto }\end{array}$ & $\begin{array}{c}\text { Profundidade } \\
\text { de coleta }\end{array}$ & Rede & $\begin{array}{l}\text { Malha } \\
(\mu \mathrm{m})\end{array}$ & $\begin{array}{l}\text { No. de } \\
\text { inds. }\end{array}$ \\
\hline 1216 & $22^{\circ} 02^{\prime} 30,0^{\prime \prime}$ & $039^{\circ} 49^{\prime} 41,2^{\prime \prime}$ & $12 / 05 / 2002$ & oblíquo & $1.000 \mathrm{~m}$ & cilíndrico-cônica & 500 & 2 \\
\hline 5447 & $21^{\circ} 57^{\prime} 10,5^{\prime \prime}$ & $039^{\circ} 43^{\prime} 33,3^{\prime \prime}$ & 09/10/2001 & oblíquo & $1.000 \mathrm{~m}$ & cilíndrico-cônica & 500 & 1 \\
\hline 5448 & $21^{\circ} 54^{\prime} 36,5^{\prime \prime}$ & $039^{\circ} 45^{\prime} 20,0^{\prime \prime}$ & 09/10/2001 & oblíquo & $\mathrm{m}$ & cilíndrico-cônica & 0 & 1 \\
\hline 5452 & $21^{\circ} 54^{\prime} 36,5^{\prime \prime}$ & $039^{\circ} 45^{\prime} 20,0^{\prime \prime}$ & $10 / 10 / 2001$ & oblíquo & $1.000 \mathrm{~m}$ & cilíndrico-cônica & 500 & 2 \\
\hline 5454 & $21^{\circ} 54^{\prime} 36,5^{\prime \prime}$ & $039^{\circ} 45^{\prime} 20,0^{\prime \prime}$ & 10/10/2001 & oblíquo & $1.000 \mathrm{~m}$ & cilíndrico-cônica & 500 & 1 \\
\hline 5456 & $21^{\circ} 53^{\prime} 10,4^{\prime \prime}$ & $039^{\circ} 45^{\prime} 49,9^{\prime \prime}$ & $10 / 10 / 2001$ & oblíquo & & cilíndrico-cônica & 500 & 1 \\
\hline 5461 & $21^{\circ} 58^{\prime} 31,0^{\prime \prime}$ & $039^{\circ} 50^{\prime} 29,7^{\prime \prime}$ & $11 / 10 / 2001$ & oblíquo & $1.000 \mathrm{~m}$ & cilíndrico-cônica & 500 & 2 \\
\hline 5462 & $22^{\circ} 32^{\prime} 50,0^{\prime \prime}$ & $040^{\circ} 04^{\prime} 09,9^{\prime \prime}$ & 06/11/2001 & oblíquo & $1.000 \mathrm{~m}$ & cilíndrico-cônica & 500 & 4 \\
\hline 7455 & $22^{\circ} 32^{\prime} 50,0^{\prime \prime}$ & $040^{\circ} 04^{\prime} 09,9^{\prime \prime}$ & 06/11/2001 & oblíquo & $0 \mathrm{~m}$ & cilíndrico-cônica & 500 & 4 \\
\hline 7457 & $22^{\circ} 32^{\prime} 50,0^{\prime \prime}$ & $040^{\circ} 04^{\prime} 09,9^{\prime \prime}$ & $06 / 11 / 2001$ & oblíquo & $1.000 \mathrm{~m}$ & cilíndrico-cônica & 500 & 4 \\
\hline 7458 & $22^{\circ} 32^{\prime} 49,0^{\prime \prime}$ & $040^{\circ} 04^{\prime} 20,9^{\prime \prime}$ & $07 / 11 / 2001$ & oblíquo & $1.000 \mathrm{~m}$ & cilíndrico-cônica & 500 & 2 \\
\hline 7464 & $22^{\circ} 32^{\prime} 49,0^{\prime \prime}$ & $040^{\circ} 04^{\prime} 20,9^{\prime \prime}$ & $07 / 11 / 2001$ & oblíquo & $1.000 \mathrm{~m}$ & cilíndrico-cônica & 500 & 2 \\
\hline 7465 & $22^{\circ} 31^{\prime} 40,9^{\prime \prime}$ & $040^{\circ} 02^{\prime} 39,6^{\prime \prime}$ & $07 / 11 / 2001$ & oblíquo & $1.000 \mathrm{~m}$ & cilíndrico-cônica & 500 & 4 \\
\hline 7467 & $22^{\circ} 31^{\prime} 40,9^{\prime \prime}$ & $040^{\circ} 02^{\prime} 39,6^{\prime \prime}$ & $07 / 11 / 2001$ & oblíquo & $1.000 \mathrm{~m}$ & cilíndrico-cônica & 500 & 1 \\
\hline
\end{tabular}

Referências: Rofen, 1966a; Ambrose, 1966a; Bonecker et al., 2006b; Ditty, 2006b; Fahay, 2007. 


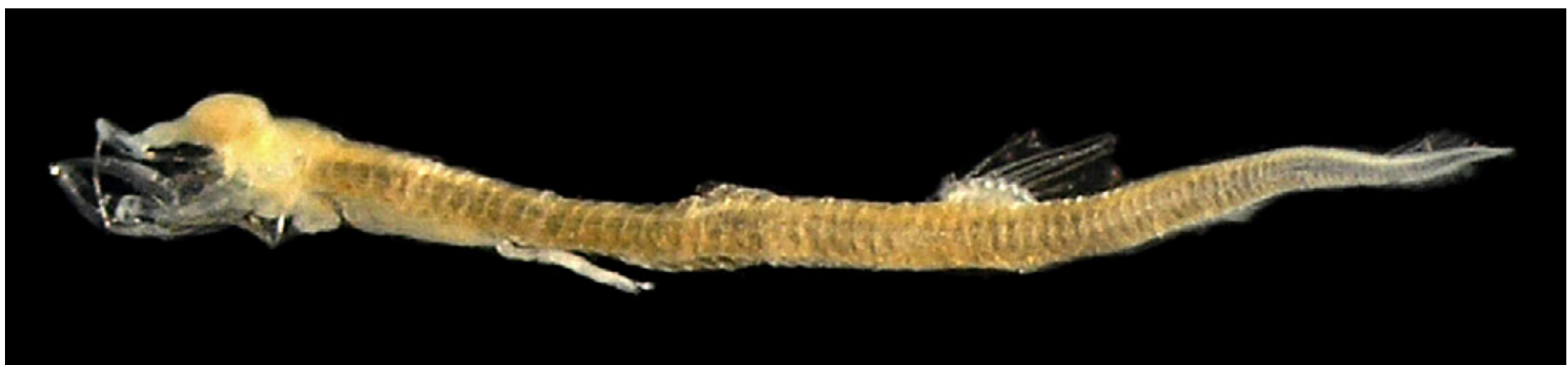

Figura 50: Uncisudis advena. DZUFRJ 13787; Pré-flexão; CP 6,6 mm.

\section{Uncisudis advena (Rofen, 1963)}

A principal característica dessa espécie é o desenvolvimento precoce das nadadeiras dorsal e pélvica. A nadadeira pélvica está situada na mesma direção da origem da nadadeira dorsal. No estágio de pré-flexão possui mancha de pigmento nas regiões dorsal e ventral da membrana embrionária caudal e cinco manchas peritoneais. Durante a flexão apresenta uma mancha na margem dorsal do pedúnculo caudal. No estágio de transformação além dessa mancha possui pigmentos na extremidade dos raios anteriores da nadadeira anal e sete manchas peritoneais. Possui aproximadamente 78 miômeros.

Tamanho: pré-flexão 6,6-8,5 mm.

Habitat: espécie marinha, mesopelágica, ocorre em profundidades entre 800 e $1.000 \mathrm{~m}$.

\section{Georreferenciamento}

\begin{tabular}{|c|c|c|c|c|c|c|c|c|}
\hline DZUFRJ & Latitude (S) & Longitude (W) & Data & $\begin{array}{l}\text { Tipo de } \\
\text { arrasto }\end{array}$ & $\begin{array}{l}\text { Profundidade } \\
\text { de coleta }\end{array}$ & Rede & $\begin{array}{c}\text { Malha } \\
(\mu \mathrm{m})\end{array}$ & $\begin{array}{l}N^{\circ} \text {. de } \\
\text { inds. }\end{array}$ \\
\hline & & & & & & & 500 & 1 \\
\hline 13787 & $21^{\circ} 58 ' 31,0^{\prime \prime}$ & $039^{\circ} 50^{\prime} 29,7^{\prime \prime}$ & $10 / 10 / 2001$ & oblíquo & $1.000 \mathrm{~m}$ & cilíndrico-cônica & 500 & 1 \\
\hline
\end{tabular}

Referência: Rofen, 1966a; Bonecker et al., 2006b; Ditty, 2006b; Fahay, 2007. 


\section{Família Anotopteridae}

A família Anotopteridae é mono-específica representada por Anotopterus pharao. Essa espécie é mesopelágica e batipelágica, encontrada em águas temperadas e polares. 


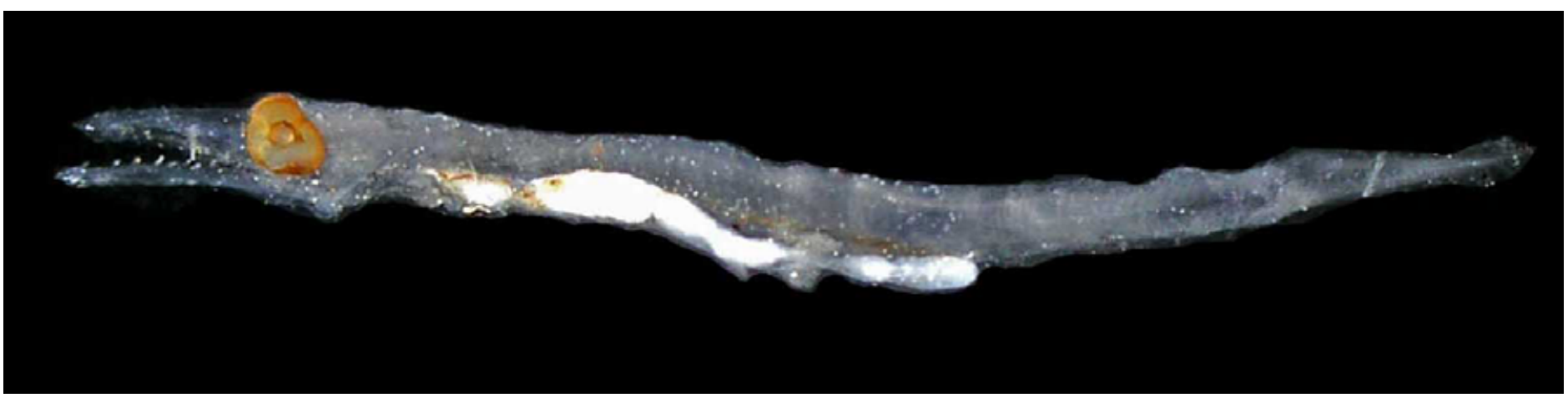

Figura 51: Anotopterus pharao. DZUFRJ 7508; Flexão; CP 11,0 mm.

\section{Anotopterus pharao Zugmayer, 1911}

Diferentemente dos demais representantes de Aulopiformes, essa espécie não possui pigmentos peritoneais. Possui o corpo fino e alongado (76 a 80 miômeros) com intestino alcançando mais da metade do comprimento padrão (no máximo $60 \%$ do CP). O focinho é alongado e possui projeções cartilaginosas nas extremidades das maxilas, com pigmento na inferior. Presença de dentes caninos em cada osso do palato, desde a pré-flexão. Ausência de nadadeira dorsal e presença de nadadeira adiposa.

Tamanho: flexão 11,0 mm.

Habitat: espécie marinha, mesopelágica e batipelágica, ocorre em profundidades entre 500 e $2.000 \mathrm{~m}$.

\section{Georreferenciamento}

\begin{tabular}{|c|c|c|c|c|c|c|c|c|}
\hline DZUFRJ & Latitude (S) & Longitude (W) & Data & $\begin{array}{c}\text { Tipo de } \\
\text { arrasto }\end{array}$ & $\begin{array}{c}\text { Profundidade } \\
\text { de coleta }\end{array}$ & Rede & $\begin{array}{c}\text { Malha } \\
\left.\text { ( } \boldsymbol{\mu m}^{\circ}\right)\end{array}$ & $\begin{array}{c}\mathbf{N}^{\circ} \text {. de } \\
\text { inds. }\end{array}$ \\
\hline 7508 & $21^{\circ} 57^{\prime} 10,5^{\prime \prime}$ & $039^{\circ} 43^{\prime} 33,3^{\prime \prime}$ & $9 / 10 / 2001$ & oblíquo & $1.000 \mathrm{~m}$ & cilíndrico-cônica & 500 & 1 \\
\hline
\end{tabular}

Referências: Ambrose, 1996b; Ditty, 2006b; Fahay, 2007. 


\section{Família Evermannellidae}

A família Evermannellidae é marinha e ocorre nos oceanos Atlântico, Índico e Pacífico. Compreende três gêneros com sete espécies. Possuem três manchas no peritôneo com exceção da espécie Odontostomops normalops que apresenta 13 a 15 manchas. Nos estágios iniciais de desenvolvimento possuem pigmentos no miossepto formando bandas descontínuas.

No Brasil já foram identificadas quatro espécies nas fases de larva e adulto: Coccorella atlantica (Parr, 1928); Evermannella balbo (Risso, 1820); Evermannella melanoderma Parr, 1928 e Odontostomops normalops (Parr, 1928). Nesse estudo são contempladas as espécies Coccorella atlantica, Evermannella balbo e Evermannella melanoderma. 


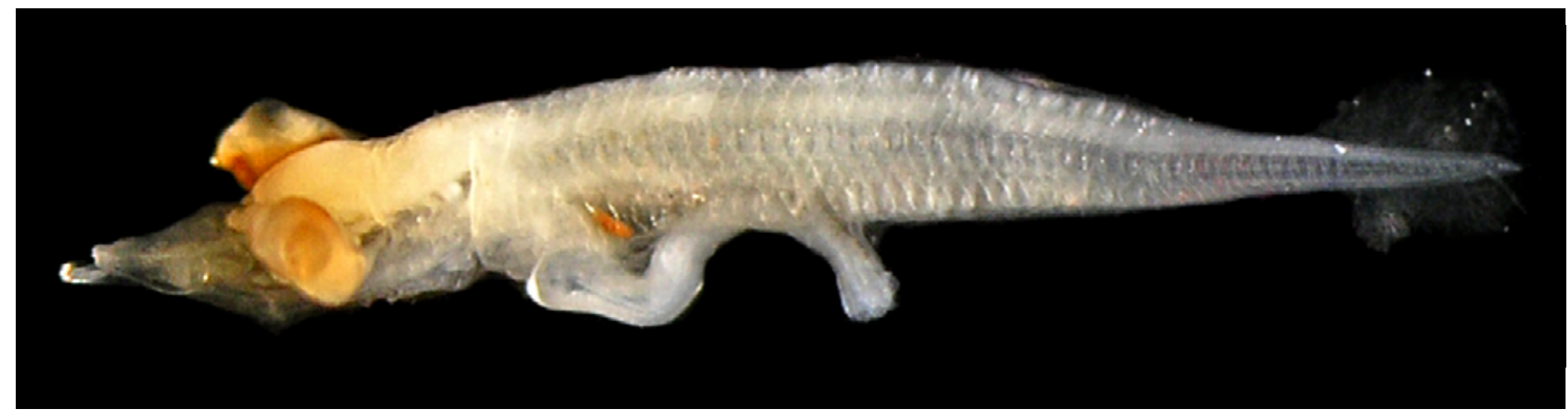

Figura 52 - A: Coccorella atlantica. DZUFRJ 13153; Pré-flexão; CP 3,5 mm.

\section{Coccorella atlantica (Parr, 1928)}

Nos estágios de pré-flexão e de flexão as larvas dessa espécie possuem três manchas peritoneais. No estágio de pós-flexão têm cinco bandas de pigmento na parte dorsal do corpo e quatro na região ventral.

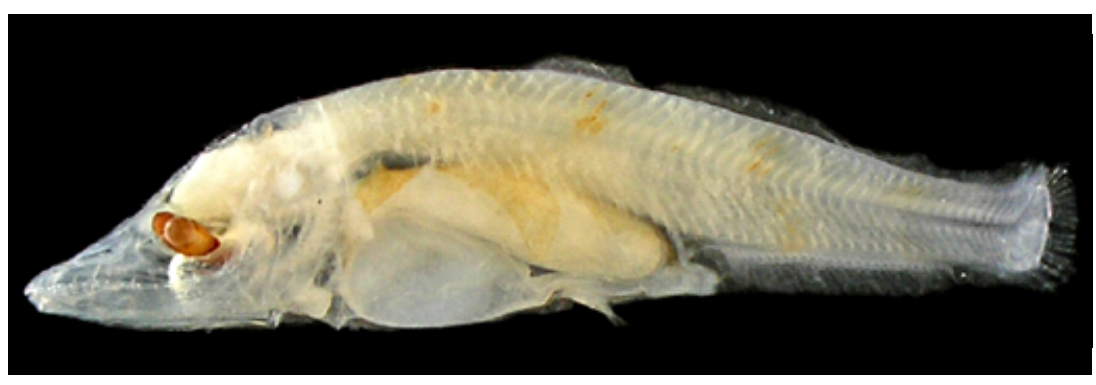

Figura 52 - B: DZUFRJ 15242; Flexão; CP 7,0 mm. O olho é elíptico, a nadadeira dorsal tem 12 raios e a anal tem 25 ou 26 raios. O número de miômeros varia entre 48 e 53. Presença de nadadeira adiposa a partir da pós-flexão.

Tamanho: pré-flexão 3,5-5,0 mm; flexão 6,5-7,0 mm.

Habitat: espécie marinha, mesopelágica, ocorre em águas tropicais e temperadas quentes em profundidades entre 100 e 500 m, principalmente entre 50 e $125 \mathrm{~m}$.

\section{Georreferenciamento}

\begin{tabular}{|c|c|c|c|c|c|c|c|c|}
\hline DZUFRJ & Latitude (S) & Longitude (W) & Data & $\begin{array}{l}\text { Tipo de } \\
\text { arrasto }\end{array}$ & $\begin{array}{l}\text { Profundidade } \\
\text { de coleta }\end{array}$ & Rede & $\begin{array}{c}\text { Malha } \\
(\mu \mathrm{m})\end{array}$ & $\begin{array}{l}N^{\circ} \text {. de } \\
\text { inds. }\end{array}$ \\
\hline 5401 & $22^{\circ} 32^{\prime} 49,0^{\prime \prime}$ & $040^{\circ} 04^{\prime} 20,9^{\prime \prime}$ & $07 / 11 / 2001$ & oblíquo & $1.000 \mathrm{~m}$ & cilíndrico-cônica & 500 & 3 \\
\hline 7393 & $21^{\circ} 53^{\prime} 10,4^{\prime \prime}$ & $039^{\circ} 45^{\prime} 49,9^{\prime \prime}$ & 10/10/2001 & oblíquo & $1.000 \mathrm{~m}$ & cilíndrico-cônica & 500 & 1 \\
\hline 7396 & $21^{\circ} 58^{\prime} 31,0^{\prime \prime}$ & $039^{\circ} 50^{\prime} 29,7^{\prime \prime}$ & 10/10/2001 & oblíquo & $1.000 \mathrm{~m}$ & cilíndrico-cônica & 500 & 5 \\
\hline 7397 & $21^{\circ} 53^{\prime} 10,4^{\prime \prime}$ & $039^{\circ} 45^{\prime} 49,9^{\prime \prime}$ & $10 / 10 / 2001$ & oblíquo & $1.000 \mathrm{~m}$ & cilíndrico-cônica & 500 & 2 \\
\hline 24176 & $21^{\circ} 58^{\prime} 31,0^{\prime \prime}$ & $039^{\circ} 50^{\prime} 29,7^{\prime \prime}$ & $11 / 10 / 2001$ & oblíquo & $1.000 \mathrm{~m}$ & cilíndrico-cônica & 500 & 1 \\
\hline 24177 & $21^{\circ} 58 ' 31,0^{\prime \prime}$ & $039^{\circ} 50^{\prime} 29,7^{\prime \prime}$ & $10 / 10 / 2001$ & oblíquo & $1.000 \mathrm{~m}$ & cilíndrico-cônica & 500 & 1 \\
\hline
\end{tabular}

Referências: Rofen, 1966b; Bonecker et al., 2006b; Ditty, 2006c; Fahay, 2007. 


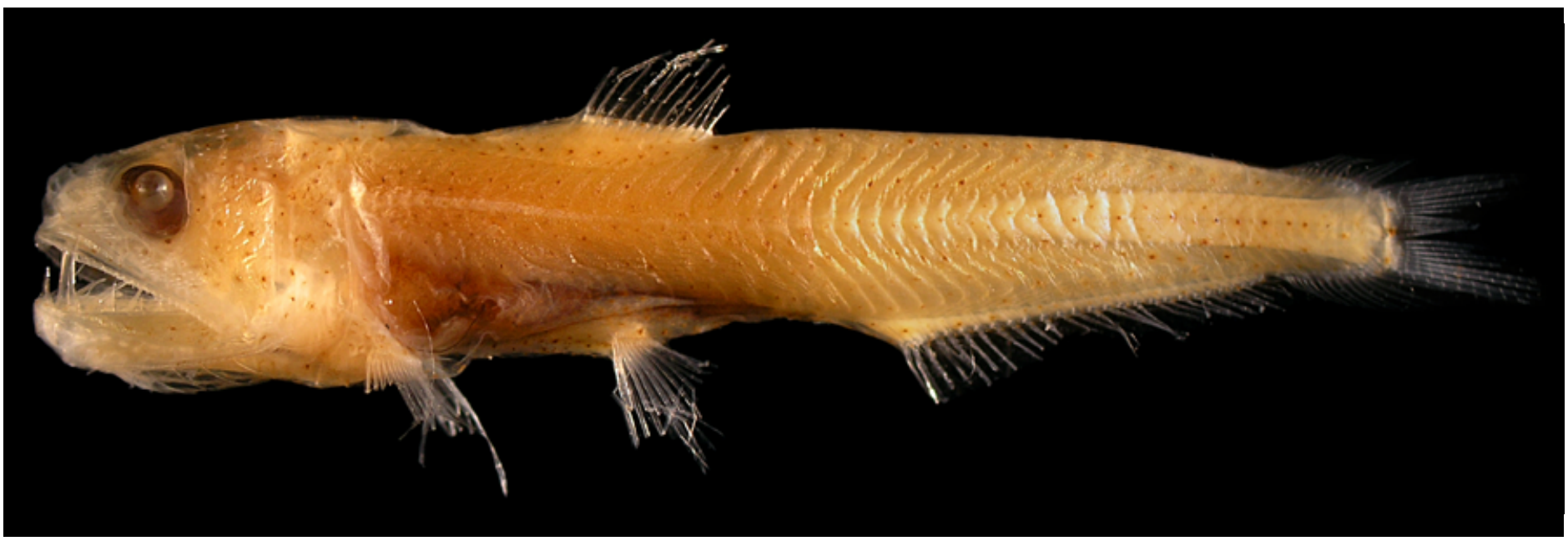

Figura 53: Evermannella balbo. DZUFRJ 5399; Juvenil; CP 28,0 mm.

\section{Evermannella balbo (Risso, 1820)}

Nos estágios de pré-flexão e de flexão possui três manchas peritoneais. Em pós-flexão as larvas têm de sete a oito bandas de pigmento na parte dorsal do corpo e de quatro a cinco na região ventral. O olho é elíptico, a nadadeira dorsal tem 12 a 13 raios e a anal tem 33 a 36 raios. Nos juvenis a cabeça fica mais arredondada e os olhos ficam menos elípticos. O número de miômeros varia entre 52 e 54. Os juvenis começam a desenvolver o padrão de pigmentação dos adultos, com melanóforos grandes alinhados em fila na região posterior do corpo. Apresentam também uma banda vertical na região do pedúnculo caudal.

Tamanho: pré-flexão 6,0 mm; juvenil 28,0 mm.

Habitat: espécie marinha, mesopelágica, ocorre em águas temperadas em profundidades entre 100 e $800 \mathrm{~m}$.

\section{Georreferenciamento}

\begin{tabular}{|c|c|c|c|c|c|c|c|c|}
\hline DZUFR & Latitude (S) & Longitude (W) & Data & $\begin{array}{c}\text { Tipo de } \\
\text { arrasto }\end{array}$ & $\begin{array}{c}\text { Profundidade } \\
\text { de coleta }\end{array}$ & Rede & $\begin{array}{c}\text { Malha } \\
\text { ( } \boldsymbol{\mu m})\end{array}$ & $\begin{array}{c}\mathbf{N}^{\circ} \text {. de } \\
\text { inds. }\end{array}$ \\
\hline 5399 & $22^{\circ} 31^{\prime} 40,9^{\prime \prime}$ & $040^{\circ} 02^{\prime} 39,6^{\prime \prime}$ & $07 / 11 / 2001$ & oblíquo & $1.000 \mathrm{~m}$ & cilíndrico-cônica & 500 & 1 \\
\hline 7394 & $21^{\circ} 58^{\prime} 31,0^{\prime \prime}$ & $039^{\circ} 50^{\prime} 29,7^{\prime \prime}$ & $11 / 10 / 2001$ & oblíquo & $1.000 \mathrm{~m}$ & cilíndrico-cônica & 500 & 1 \\
\hline
\end{tabular}

Referências: Rofen, 1966b; Bonecker et al., 2006b; Ditty, 2006c; Fahay, 2007. 


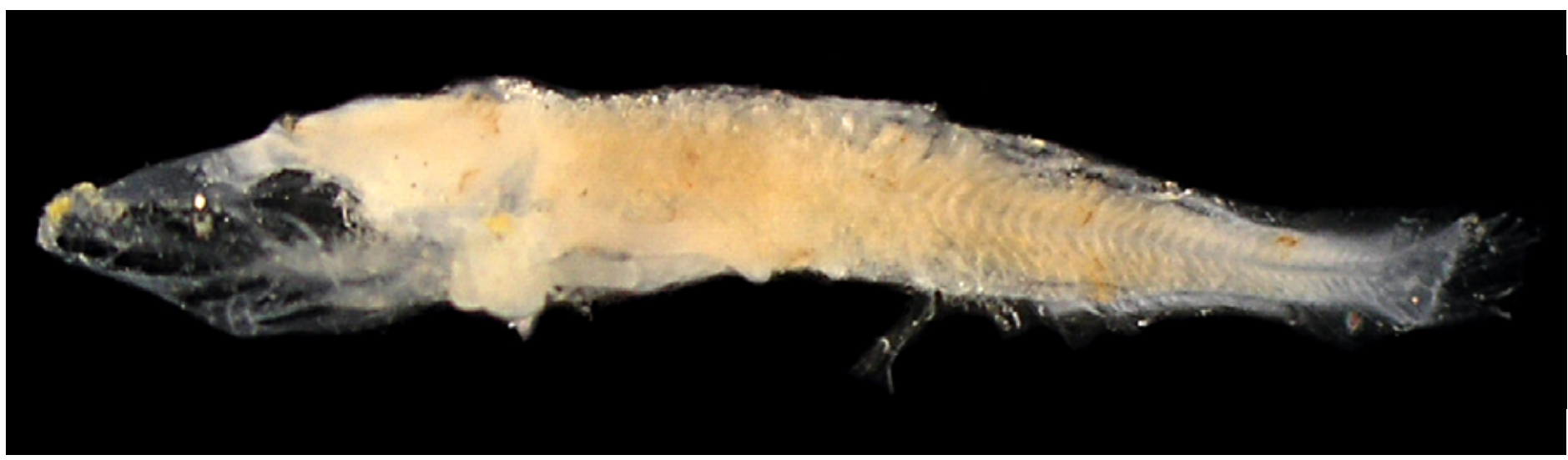

Figura 54: Evermannella melanoderma. DZUFRJ 7395; Flexão; CP 6,5 mm.

\section{Evermannella melanoderma Parr, 1928}

Nos estágios de pré-flexão e de flexão possui três manchas peritoneais. Tem duas linhas de cromatóforos ao longo do corpo, uma na região dorsal e outra na parte ventral, sobre a nadadeira anal. O olho é elíptico, a nadadeira dorsal tem 12 a 13 raios e a anal tem 27 a 31 raios. 0 número de miômeros varia entre 49 e 50.

Tamanho: flexão 6,5 mm.

Habitat: espécie marinha, mesopelágica, ocorre em águas tropicais e temperadas quentes em profundidades entre 100 e $800 \mathrm{~m}$.

\section{Georreferenciamento}

\begin{tabular}{|c|c|c|c|c|c|c|c|c|}
\hline DZUFRJ & Latitude (S) & Longitude (W) & Data & $\begin{array}{c}\text { Tipo de } \\
\text { arrasto }\end{array}$ & $\begin{array}{c}\text { Profundidade } \\
\text { de coleta }\end{array}$ & Rede & $\begin{array}{c}\text { Malha } \\
(\boldsymbol{\mu m})\end{array}$ & $\begin{array}{c}\mathbf{N}^{\circ} \text {. de } \\
\text { inds. }\end{array}$ \\
\hline 7395 & $21^{\circ} 54^{\prime} 36,5^{\prime \prime}$ & $039^{\circ} 45^{\prime} 20,0^{\prime \prime}$ & $10 / 10 / 2001$ & oblíquo & $1.000 \mathrm{~m}$ & cilíndrico-cônica & 500 & 1 \\
\hline
\end{tabular}

Referências: Rofen, 1966b; Bonecker et al., 2006b; Ditty, 2006c; Fahay, 2007. 